\title{
Market Discipline and Internal Governance in the Mutual Fund Industry*
}

\author{
Thomas Dangl \\ Institute of Management Science \\ Vienna University of Technology \\ Theresianumgasse 27, A-1040 Vienna \\ Phone:0043-58801-33063 \\ thomas.dangl@tuwien.ac.at \\ Youchang Wu \\ Department of Finance, University of Vienna \\ Bruennerstrasse 72, 1210 Vienna \\ Phone:0043-1-4277-38211 \\ youchang.wu@univie.ac.at \\ Josef Zechner \\ Department of Finance, University of Vienna \\ Bruennerstrasse 72, 1210 Vienna \\ Phone:0043-1-4277-38072 \\ josef.zechner@univie.ac.at \\ First version: January 2004 \\ This version: February 2005
}

\footnotetext{
*A previous version of this paper, entitled "Mutual Fund Flows and Optimal Manager Replacement" has been presented at seminars at the University of Vienna, University of Tübingen, City University London, Lancaster University, the European Finance Association 2004 meeting in Maastricht, and the German Finance Association 2004 meeting in Tübingen. We thank Michael Brennan, Engelbert Dockner, Robert Elliot, Marcin Kacperczyk, Kristian Miltersen, Neal Stoughton, Russ Wermers, Stefan Zeisberger, and seminar participants for valuable suggestions and comments. Youchang Wu and Josef Zechner gratefully acknowledge the financial support by the Austrian Science Fund (FWF) under grant SFB 010 and by the Gutmann Center for Portfolio Management at the University of Vienna.
} 


\begin{abstract}
This paper develops a continuous-time model in which a portfolio manager is hired by a management company. Based on past portfolio returns, all agents update their beliefs about the manager's skills. In response, investors can move capital into or out of the mutual fund, the portfolio manager can alter the risk of the portfolio and the management company can replace the manager. We examine the resulting interaction between internal governance and product market discipline and generate a rich set of predictions on mutual fund flows, portfolio risk, portfolio manager turnovers, and the value of the management company. In particular we derive the optimal manager replacement rule of the fund management company and show how it is influenced by the uncertainty about managerial skills, manager tenure and other model parameters. For reasonable parameterizations, the firing of a portfolio manager is accompanied by a capital inflow and a portfolio risk reduction. If the belief about managerial skills becomes more precise over time, then the firing threshold increases with manager tenure. Our model also shows how fund inflows are related to fund performance, fund size, and uncertainty about managerial skills. While we find that fund size tends to increase with manager tenure, the value of the management company as a percentage of assets under management tends to decrease.
\end{abstract}


The portfolio management industry has undergone dramatic growth in the last few decades, thereby also generating an increasing interest among regulators and academics. The question how to ensure efficient governance of delegated portfolio management has attracted particular attention. Most theoretical models have addressed this question using the standard principal-agent paradigm, characterizing the optimal contracts that alleviate the agency problem between fund investors and managers. ${ }^{1}$ Several empirical studies have investigated the effectiveness of incentive fees ${ }^{2}$ and, in a somewhat different vein, the role of funds' boards of directors in controlling agency costs. ${ }^{3}$

This paper takes a broader view of the governance mechanisms in the portfolio management industry by explicitly taking into account the role of the product market. A key characteristic of the mutual fund industry is that fund investors are at the same time consumers. The open-end structure of mutual funds allows individual investors to "fire" the fund manager by withdrawing their money whenever they feel dissatisfied with the investment management services he provides. This not only disciplines the manager directly, as pointed out by Fama and Jensen (1983), but also gives the management company strong incentives to fire underperforming managers in order to avoid losing market share. On the other hand, the fund's internal governance actions, such as the firing of an underperforming manager, will also have an impact on investors' capital allocation. We formalize the product market discipline via fund flows and the internal manager replacement decision simultaneously in a fully-dynamic framework. Our model shows that the interplay between these two alternative governance mechanisms is the key to understand many phenomena observed in the mutual fund market.

In our model, the portfolio manager may have some stock picking ability that generates an expected rate of abnormal return by taking idiosyncratic risks. However, active portfolio management exhibits a diseconomy of scale, as introduced by Berk and Green (2004). Furthermore, the manager's ability to manage a specific fund is not known either to the management company, to the fund investors or to the manager himself. All agents in the model only know a common prior distribution of the ability and keep updating their beliefs using the

\footnotetext{
${ }^{1}$ See, for example, Stoughton (1993), Heinkel and Stoughton (1994), Admati and Pfleiderer (1997), Das and Sundaram (2002), Ou-Yang (2003).

${ }^{2}$ See, for example, Elton, Gruber, and Blake (2003).

${ }^{3}$ See, for example, Tufano and Sevick (1997) for the case of open-end funds and Guercio, Dann, and Partch (2003) for the case of closed-end funds.
} 
observed fund performance. Investors have perfect mobility, they can move money into or out of a fund without any cost. Within such a framework, we address the following questions:

(i). How can managerial ability be learned from realized fund returns?

(ii). Given the belief about managerial ability, what is the equilibrium fund size and the optimal level of idiosyncratic risk a manager should take?

(iii). What are the determinants of fund flows?

(iv). Given the mobility of fund investors, what is the optimal manager replacement rule for the fund management company?

(v). How do investors react to an observed manager change? How does the fund risk change as the underperforming manager is replaced?

(vi). What are typical valuation levels and their comparative statics for portfolio management companies in the presence of market discipline and internal governance?

We develop a continuous-time Bayesian learning model to characterize the inference of managerial ability and derive an equilibrium relation between the belief about managerial ability, fund size and fund risk. This equilibrium relation allows us to derive the flow dynamics in a very straightforward way. We interpret the management company's right to replace the manager as an American put option written on the stochastic process of the belief and derive the optimal replacement threshold using a real options approach. We show how the optimal replacement threshold, the value of the management company, and manager tenure depend on various parameters. The comparative statics of the optimal replacement threshold in turn generates cross-sectional predictions about the response of fund flows to manager replacement and the change of fund risk around manager replacement.

When deriving the optimal manager replacement rule, we first consider a special case in which the precision of the belief about managerial ability remains constant. This allows us to derive the constant optimal replacement threshold analytically. We then consider the case in which the precision of the belief improves over time and derive the tenure-dependent replacement threshold numerically. Our results show that the threshold increases substantially 
over the manager's tenure and that the value of the management company increases with the variability of the true managerial ability.

Since the early 1990s, considerable effort has been devoted to research on the behavior of mutual fund flows. It is well documented that there is a strong positive relation between a fund's money inflows and its past performance, indicating that investors are chasing good past performers. ${ }^{4}$ Similar to Berk and Green (2004), our model generates results where rational investors behave in a way fully consistent with this empirical observation. Another stylized fact that has attracted much attention is that the flow-performance relation is not only positive but also convex, meaning that out-performers receive disproportionately more fund inflows, while under-performers are not penalized in an offsetting manner. ${ }^{5}$ This convexity implies a positive expected rate of net fund inflows which we derive from our model. In addition, it has also been documented that fund inflows, as well as their volatility and sensitivity to past performance, are negatively correlated with fund size and fund age. ${ }^{6}$ Finally, Warther (1995) reports a negative relation between the market return and subsequent aggregate fund inflows. Our model implies all these empirical regularities. ${ }^{7}$

There is also a strand of literature on the turnover of portfolio managers. Khorana (1996) documents an inverse relation between the probability of manager replacement and past fund performance, measured by asset growth rate and portfolio returns. Chevalier and Ellison (1999a) find a similar result. They also show that managerial turnover is more performancesensitive for younger managers. Chevalier and Ellison (1999b) find that managers with longer tenure tend to manage larger funds and have a higher probability to retain their positions. ${ }^{8}$ $\mathrm{Hu}$, Hall, and Harvey (2000) classify the managerial departure into promotion and demotion, and find that the probability of demotion is negatively correlated with the fund's current and past performance whereas the probability of promotion is positively related to the fund's

\footnotetext{
${ }^{4}$ See, for example, Ippolito (1992), Gruber (1996), Chevalier and Ellison (1997), Sirri and Tufano (1998), Bergstresser and Poterba (2002),and Boudoukh, Richardson, Stanton, and Whitelaw (2003).

${ }^{5}$ See Chevalier and Ellison (1997) and Sirri and Tufano (1998).

${ }^{6}$ See, for example, Chevalier and Ellison (1997), Sirri and Tufano (1998), Bergstresser and Poterba (2002), Boudoukh, Richardson, Stanton, and Whitelaw (2003).

${ }^{7}$ Gruber (1996) and Zheng (1999) find that money inflows are positively related to the subsequent fund performance, indicating that investors might be able to make buying and selling decisions based on good assessment of future fund performance. However, Sapp and Tiwari (2004) find that this "smart money" effect disappears after controlling for the stock return momentum effect documented by Jegadeesh and Titman (1993).

${ }^{8}$ The positive tenure-fund size relation is also documented by Fortin, Michelson, and Jordan-Wagner (1999) and Boyson (2003).
} 
current and past performance. Khorana (2001) documents significant performance improvements after the replacement of an underperforming manager and significant performance deteriorations after the replacement of outperforming managers. Ding and Wermers (2004) find that fund managers underperform their counterparts during the year of their replacement, and the underperformance vanishes after the manager is replaced. All these findings are in accordance with the predictions from our model.

Several theoretical models have been advanced to explain subsets of the phenomena mentioned above. Berk and Green (2004) present an interesting discrete-time learning model to explain one seemingly puzzling phenomenon: Given that the evidence on the predictability of fund performance is rather weak, why do investors always chase past winners? There are three key elements in their answer to this question: First, there is competitive provision of capital by investors to mutual funds. Second, there is decreasing return to scale in active portfolio management. Finally, past returns contain information about managerial ability. The combination of these three elements explains both the lack of performance persistence and the flow-performance relation: Good performance leads to higher assessment of managerial ability and fund inflows, which in turn hurts future fund performance due to the decreasing return to scale. Since the capital provision is competitive, the fund size will be adjusted to a level where no predictability in fund performance exists. Our model on mutual fund flows incorporates all three key elements of Berk and Green (2004). However, in contrast to Berk and Green (2004), we explicitly distinguish between fund management companies and fund managers. While Berk and Green (2004) assume an exogenous shut-down threshold, we allow the fund management company to replace the manager if it is optimal to do so. This not only enables us to explain both fund flows and managerial turnover in a unified framework, but also sheds new light on the flow-performance relation. In particular, our model generates predictions about fund flows and risk changes around manager replacement. Furthermore, we are able to derive closed-form solutions for the value of the management company, accounting for both market discipline and the real option generated by optimal manager replacement.

Lynch and Musto (2003) develop a two-period model to explain the convexity of the flow-performance relation. Their key insight is that underperforming funds will change their strategies while those outperforming will not. Therefore bad past performance contains less 
information about future performance than good past performance does. Taking this effect into account, rational investors will be less sensitive to past performance when it is poor. Our model differs from the Lynch and Musto (2003) model in several aspects. First, Lynch and Musto (2003) do not allow for diseconomies of scale. As a result, active funds will on average earn above normal returns and good performance should exhibit strong persistence. Both of these implications are in contradiction with the majority of empirical findings. Second, whereas Lynch and Musto (2003) analyze the decision to change strategies in a twoperiod model, we model the manager replacement decision in a fully dynamic framework, taking into account flow responses, replacement costs, and the option value of postponing the replacement. Third, although firing bad managers increases the convexity of the flowperformance relation, such a convexity exists in our model even without this consideration.

The rest of the paper is structured as follows: Section 1 analyzes the dynamics of equilibrium fund size and the determinants of fund flows. Section 2 examines the optimal manager replacement rule when the precision of the belief about managerial ability remains constant over time. Section 3 reexamines this issue for the case in which the precision of the belief about managerial ability improves over time. Section 4 analyzes flow responses and risk changes around manager replacement. Section 5 concludes.

\section{Learning and mutual fund flows}

\subsection{The dynamics of NAV}

The net asset value per share, denoted by NAV, of an open-end fund is assumed to evolve as follows:

$$
\frac{d N A V_{t}}{N A V_{t}}=\left[r+\lambda \sigma_{m}+\alpha_{t}-\delta_{t}-b_{t}\right] d t+\sigma_{m} d W_{m t}+\sigma_{i t} d W_{i t}
$$

where $r$ is the risk free rate, $\lambda$ is the market price of risk, $\alpha_{t}$ is the expected rate of abnormal return generated by the manager due to his stock-picking ability, $W_{m t}$ and $W_{i t}$ are two uncorrelated standard Wiener processes driving the stochastic part of the market return and the idiosyncratic component of the fund's return respectively. The subscript $t$ denotes the 
incumbent manager's tenure, $\sigma_{m}$ is the fund's constant exposure to market risk while $\sigma_{i t}$ is the fund's time-varying exposure to idiosyncratic risk, $\delta_{t}$ is the instantaneous dividend yield and $b_{t}$ is the instantaneous management fee ratio.

Our specification of the $N A V$ dynamics explicitly accounts for active portfolio management. The term $r+\lambda \sigma_{m}$ is the fair return given the fund's exposure to systematic risk. The expected rate of abnormal return, $\alpha_{t}$, can be interpreted as Jensen's $\alpha$. The dividend yield, $\delta_{t}$, and the management fee ratio, $b_{t}$, are subtracted from the $N A V$ return because they represent cash paid out to the investors and the management company respectively. The exposure to market risk, $\sigma_{m}$, is assumed to be constant since we do not intend to model the manager's market-timing ability. ${ }^{9}$ In contrast to the constant exposure to the market risk, the fund's exposure to the idiosyncratic risk, $\sigma_{i t}$, can be changed by the manager at any time, under the constraint that it must be positive.

The expected abnormal rate of return is assumed to have the following functional form:

$$
\alpha_{t}=\sigma_{i t}\left(\theta_{t}-\gamma A_{t} \sigma_{i t}\right)
$$

where $\theta_{t}$ is the incumbent manager's stock-picking ability, $A_{t}$ is the market value of assets under management and $\gamma$ is a positive constant characterizing the decreasing return to scale in active portfolio management.

The manager's ability, $\theta_{t}$, is assumed to be fund specific, which implies that the manager's track record in other funds does not matter. Thus, we assume that the abnormal return is a joint product of the manager and the management company. A good manager in one company is not necessarily a good manager in another company because every company has its own organizational structures, research networks and business culture. This assumption implies that our model is essentially a matching model in the spirit of Jovanovic (1979). It allows us to abstract from the observable heterogeneity among the manager candidates available to replace the incumbent manager.

Our specification of the expected abnormal return has several desirable features. First,

\footnotetext{
${ }^{9}$ There is little evidence showing that mutual fund managers have market-timing ability. However, recent studies using portfolio holdings data do provide support for the notion that some managers have superior stockpicking ability. See, for example, Grinblatt and Titman (1993), Daniel, Grinblatt, Titman, and Wermers (1997), Wermers (2000).
} 
the expected abnormal return per unit of idiosyncratic risk, i.e., $\theta_{t}-\gamma A_{t} \sigma_{i t}$, is positively related to managerial ability $\theta_{t}$, negatively related to fund size $A_{t}$ and idiosyncratic risk $\sigma_{i t}$. This implies that active portfolio management exhibits diseconomies of scale and that the marginal return of taking idiosyncratic risk is decreasing. As discussed in Berk and Green (2004), an important reason for the diseconomy of scale is the price impact of large portfolio transactions. Consider a manager who is able to identify a small number of undervalued stocks. If he is managing a small fund, he can invest the entire fund capital in these stocks and earn a high abnormal rate of return. However, if he is managing a large fund, doing so would move the prices of those stocks and erode his performance. ${ }^{10}$ Decreasing return to taking idiosyncratic risk is a necessary condition to rule out unlimited expected profit opportunity.

Second, there is an interaction between fund size and idiosyncratic risk. This has two implications: (1) The larger the fund size, the smaller the marginal return of taking idiosyncratic risk. This should be the case due to the larger price impact associated with larger fund size. (2) the more idiosyncratic risk a fund takes, the larger the diseconomy of scale it has to face. A fund with high idiosyncratic risk may either concentrate on a small number of securities, or hold illiquid stocks. Such funds would suffer the most from being large. However, a well-diversified fund, such as an index fund, will not be hurt as much by its large size. ${ }^{11}$

\subsection{Inference about managerial ability}

We assume that neither the fund management company, nor the fund investors, nor the manager himself, can observe the managerial ability $\theta_{t}$ directly. Therefore, the $W_{i t}$ process is not observable either. In other words, when agents in our model observe a high (low) market

\footnotetext{
${ }^{10}$ Many authors have investigated this issue empirically. See for example, Perold and Salomon (1991), Indro, Jiang, Hu, and Lee (1999), Chen, Hong, Huang, and Kubik (2004).

${ }^{11}$ Our formulation of the abnormal return can be interpreted in another way. Suppose the manager divides his assets under management into two parts: one inactive part with systematic risk $\sigma_{m}$ and zero idiosyncratic risk, and one actively managed part with systematic risk $\sigma_{m}$ and idiosyncratic risk $\sigma_{\varepsilon}$. The weights of these two components are $1-w_{t}$ and $w_{t}$ respectively. The inactively managed part delivers no abnormal return and does not suffer from any diseconomy of scale. The actively managed part produces an expected rate of abnormal return due to the managerial ability $\theta$. But the abnormal return per unit of idiosyncratic risk decreases with the size of the actively managed part. It decreases faster when the idiosyncratic risk is higher, since the portfolio with higher idiosyncratic risk is less liquid. Therefore, the abnormal return of the fund can be written as
}

$$
\alpha_{t}=w_{t} \sigma_{\varepsilon}\left(\theta_{t}-w_{t} \sigma_{\varepsilon} \gamma A_{t}\right)
$$

This specification is equivalent to Equation (2) since the idiosyncratic risk of the whole portfolio is $\sigma_{i t}=w_{t} \sigma_{\varepsilon}$. 
adjusted NAV return, they cannot be sure whether this is due to good (bad) luck or due to the manager's ability. All the other terms in Equation (1) are assumed to be observable. The agents share a common prior belief: $\theta_{0}$ is normally distributed with a mean $a_{0}$ and variance $v_{0}$, and they all use Bayes' rule to update their beliefs as they observe the realized NAV process.

We assume that the true ability, $\theta_{t}$, is changing randomly over time and can be described by a driftless Wiener process:

$$
d \theta_{t}=\omega d W_{\theta t}
$$

where $\omega$ is the instantaneous volatility of the true managerial ability, $W_{\theta t}$ denotes a standard Wiener process driving $\theta_{t}$, which is assumed to be uncorrelated with the Wiener processes driving the market return and idiosyncratic return, i.e., $W_{m t}$ and $W_{i t}$. Our assumption is motivated as follows. A manager may improve his investment skill by learning from his experience and this may lead to an upward drift of $\theta_{t}$. However, it is well-recognized that the business environment is changing rapidly over time, implying that old strategies and trading models can be outdated very quickly. Sometimes past experience might even be an obstacle to future success. When these two effects offset each other on average, we end up with a driftless process for managerial ability. Our specification also nests the special case of constant true managerial ability, which corresponds to $\omega=0$.

To characterize the learning process, we substitute Equation (2) into Equation (1), and move all the directly observable terms to the left-hand side and denote the resulting expression by $d \pi_{t}$ :

$$
d \pi_{t}:=\frac{d N A V_{t}}{N A V_{t}}-\left[\left(r+\lambda \sigma_{m}-\gamma A_{t} \sigma_{i t}^{2}-\delta_{t}-b_{t}\right) d t+\sigma_{m} d W_{m t}\right]
$$

Note that $W_{m t}$ is directly observable as long as the agents know both the true expected and realized market return, which we assume they do.

Using the new notation, we can rewrite Equation (1) as

$$
d \pi_{t}=\theta_{t} \sigma_{i t} d t+\sigma_{i t} d W_{i t}
$$


Learning in our model consists of updating the belief about a manager's time-varying $\theta_{t}$ from the observed history of $d \pi$.

Given our model specifications, it follows directly from nonlinear filtering theory (see Lipster and Shiryayev (1978)) that the posterior distribution of $\theta_{t}$ is normal at every point of time. The posterior mean and variance of $\theta_{t}$, denoted by $a_{t}$ and $v_{t}$ respectively, evolve according to the following differential equation system ${ }^{12}$ :

$$
\begin{aligned}
d a_{t} & =\frac{v_{t}}{\sigma_{i t}}\left[d \pi_{t}-a_{t} \sigma_{i t} d t\right], \\
d v_{t} & =\left(\omega^{2}-v_{t}^{2}\right) d t .
\end{aligned}
$$

We refer to $v_{t}$ as the uncertainty about managerial ability and to $\frac{1}{v_{t}}$ as the precision of the belief about managerial ability.

The posterior variance is a deterministic function of the manager's tenure. It can be solved explicitly as follows,

$$
v_{t}= \begin{cases}\omega \frac{v_{0}-\omega+\left(v_{0}+\omega\right) e^{2 \omega t}}{\omega-v_{0}+\left(v_{0}+\omega\right) e^{2 \omega t}} & \text { for } \omega>0, \\ \frac{v_{0}}{v_{0} t+1} & \text { for } \omega=0\end{cases}
$$

One can easily see that $v_{t}$ converges monotonically to $\omega$ as $t$ goes to infinity. Intuitively, if we start with an a priori belief which has a high variance compared to the instantaneous volatility of true managerial ability, i.e., $v_{0}>\omega$, then the precision of our belief will improve over time, i.e., $v_{t}$ will gradually decline. However, the information can never be perfect since the true ability keeps changing over time. Therefore $v_{t}$ is bounded by $\omega$ and we have $\lim _{t \rightarrow \infty} v_{t}=\omega$. Similarly, if $v_{0}<\omega, v_{t}$ will increase over time and converge to $\omega .{ }^{13}$

When deriving the optimal replacement threshold, we first consider a special case in which $v_{0}=\omega>0$. From the above discussion it is clear that in this case the precision of the belief will not change over time, i.e., we have $v_{t}=v_{0}=\omega$. This simplifies our analysis because $v_{t}$ is not time-dependent. We then consider the case in which $v_{0}>\omega$.

\footnotetext{
${ }^{12}$ See theorem 12.1 of Lipster and Shiryayev (1978). For an intuitive explanation of the non-linear filtering theory and its applications in finance, see Gennotte (1986). Recent financial research using this technique includes Brennan (1998) and Xia (2001).

${ }^{13}$ If $\omega=0$, then $v_{t}$ converges to zero, i.e., the true ability will be perfectly learnt as the manager tenure $t$ goes to infinity.
} 
Define $Z_{t}$ as the innovation process of unexpected returns to idiosyncratic risks such that its increment $d Z_{t}$ is a normalized measure of the deviation of $d \pi_{t}$ from its posterior mean, $a_{t} \sigma_{i t} d t:$

$$
d Z_{t}:=\left[d \pi_{t}-a_{t} \sigma_{i t} d t\right] / \sigma_{i t}, Z_{0}=0 .
$$

Since $Z_{t}$ measures the unexpected idiosyncratic return, it represents the signal on which the updating of the belief will be conditioned. By construction $Z_{t}$ is a standard Wiener process conditional on the common information set of all agents in the model. Unlike the unobservable $W_{i t}$ process, the $Z_{t}$ process is derived from an observable process and is thus observable. Rewriting the dynamics of $N A V_{t}$ and $a_{t}$ in terms of $d Z_{t}$, we have:

$$
\begin{aligned}
\frac{d N A V_{t}}{N A V_{t}} & =\left[r+\lambda \sigma_{m}+\left(a_{t} \sigma_{i t}-\gamma A_{t} \sigma_{i t}^{2}\right)-\delta_{t}-b_{t}\right] d t+\sigma_{m} d W_{m t}+\sigma_{i t} d Z_{t} \\
d a_{t} & =v_{t} d Z_{t}
\end{aligned}
$$

where $v_{t}$ is given by Equation (8). Note that the instantaneous volatility of the posterior mean $a_{t}$ is the posterior variance $v_{t}$ : The less precise the belief, the more responsive it is to $d Z_{t}$.

\subsection{Equilibrium fund size}

We assume that after paying a one-time setup cost, the management company charges a proportional fee $b_{t}$ for its services. The operating cost of managing the fund, including the compensation to the fund manager, is assumed to be a fixed fraction $s$ of the total fee income. Therefore, the instantaneous net profit of the management company is $b_{t}(1-s) A_{t}$. This specification can be motivated as a linear sharing rule between the fund manager and the management company.

In the open-end fund market, investors will allocate their capital to funds whose expected rate of abnormal return is higher than the management fee and withdraw money from funds whose expected rate of abnormal return is lower than the management fee. For simplicity, we assume that such fund flows are free of charge, i.e., there is perfect capital mobility. Since there is no asymmetric information in our model, investors will update their beliefs about 
managerial ability exactly in the same way as the manager and the management company do, and they will monitor the size and idiosyncratic risk of the fund to decide whether it is worthwhile to invest in it.

Due to the diseconomy of scale, the performance of funds tends to decrease after capital inflows whereas performance tends to improve after capital outflows. Assuming that the uncertainty about managerial ability contains only diversifiable risk, the size of every fund will adjust so that the expected abnormal return is equal to the management fee, as postulated by Berk and Green (2004): ${ }^{14}$

$$
\sigma_{i t}\left(a_{t}-\gamma A_{t} \sigma_{i t}\right)=b_{t}
$$

Given an updated belief about managerial ability, the management company and the manager will choose an optimal fee $b_{t}$ and an optimal level of idiosyncratic risk $\sigma_{i t}$ to maximize the value of the management company. ${ }^{15}$ We assume that both $b_{t}$ and $\sigma_{i t}$ can be changed without any cost. Since learning about managerial ability is independent of the $b_{t}$ and $\sigma_{i t}$ processes, at any point of time, $b_{t}$ and $\sigma_{i t}$ will be set at levels that maximize the instantaneous net fee income under the investor's free movement constraint (Equation 11) and the constraints that $b_{t}, \sigma_{i t}$ and $A_{t}$ must all be positive. Formally, the manager (or the management company) solves the following maximization problem,

$$
\begin{array}{cl}
\max _{b_{t}, \sigma_{i t}} & b_{t}(1-s) A_{t} \\
\text { s.t. } & \sigma_{i t}\left(a_{t}-\gamma A_{t} \sigma_{i t}\right)=b_{t} \\
& b_{t}>0, \sigma_{i t}>0, A_{t}>0 .
\end{array}
$$

Solving for $A_{t}$ from the free movement constraint and substituting into the objective function, i.e., the net fee income, we see immediately that the net fee income depends only on the ratio $\frac{b_{t}}{\sigma_{i t}}$, but not on $b_{t}$ or $\sigma_{i t}$ per se. Since the net fee income is a quadratic function of $\frac{b_{t}}{\sigma_{i t}}$,

\footnotetext{
${ }^{14}$ Ippolito (1992), Edelen (1999) and Wermers (2000) provide supportive empirical evidence for this equilibrium condition.

${ }^{15}$ Since there is no asymmetric information, it makes no difference whether the management company or the manager sets the fee ratio and the level of idiosyncratic risk. Therefore, from now on we will adopt the convention that the fee ratio is set by the management company while the level of risk is determined by the manager.
} 
it is maximized at $\frac{b_{t}}{\sigma_{i t}}=\frac{a_{t}}{2}$. When $a_{t} \leq 0$, the problem has no solution, since the constraints cannot be met jointly. This means that managers whose estimated ability is non-positive will be driven out of business: they get no assets to manage even if they are not fired by the management company. However, when $a_{t}>0$, the management company has the flexibility of choosing any combination of $b_{t}$ and $\sigma_{i t}$ such that the ratio equals $\frac{a_{t}}{2}$. Therefore, our model does not determine a unique optimal value of $b_{t}$ or $\sigma_{i t}$, but it does predict a one-to-one correspondence between $b_{t}$ and $\sigma_{i t}$ for a given $a_{t} .{ }^{16}$

To identify the influence of beliefs about managerial ability on fund size, we assume that $b_{t}$ is constant over time and denote it by $b .{ }^{17}$ Clearly, when $b_{t}$ is fixed at $b, \sigma_{i t}$ and $A_{t}$ will be adjusted as the belief about managerial ability is updated over time. More specifically, we have the following proposition:

Proposition 1. Under conditions of perfect capital mobility and constant fee ratio $b$, the equilibrium size $A_{t}^{*}$ of an open-end fund and the optimal level of idiosyncratic risk $\sigma_{i t}^{*}$ are given by

$$
\begin{gathered}
A_{t}^{*}= \begin{cases}\frac{a_{t}^{2}}{4 b \gamma} & \text { if } a_{t}>0 \\
\text { non-existent } & \text { if } a_{t} \leq 0\end{cases} \\
\sigma_{i t}^{*}= \begin{cases}\frac{2 b}{a_{t}} & \text { if } a_{t}>0 \\
\text { non-existent } & \text { if } a_{t} \leq 0 .\end{cases}
\end{gathered}
$$

Proof. See the discussion preceding the proposition.

Several features of the equilibrium in the open-end fund market are worth mentioning.

First, the equilibrium fund size $A_{t}$ is a convex function of the posterior mean of managerial ability $a_{t}$. It is independent of a fund's dividend policy $\delta_{t}$, its systematic risk $\sigma_{m}$, the market price of risk $\lambda$, and the risk free rate $r$. Since the management fee is proportional to fund size, this implies that these factors have no influence on the fee income of the management company.

Second, the expected abnormal return to the open-end fund investors is zero (see Equa-

\footnotetext{
${ }^{16}$ Golec (1996) documents a positive relation between management fee ratio and fund idiosyncratic risk.

${ }^{17}$ In practice, management fees are usually very stable. Thus our assumption accords well with empirical evidence.
} 
tion (11)). This does not imply that managerial ability does not exist, it just means that the investors cannot benefit from it because the provision of capital is competitive. All the economic rents generated by managerial ability are captured by the manager and the management company. Therefore manager ability is better measured by the fund size and management fee than by the return to fund investors.

Third, the level of idiosyncratic risk $\sigma_{i t}$ is negatively related to the posterior mean of managerial ability $a_{t}$. This is counter-intuitive because one might expect managers with higher estimated ability to take higher idiosyncratic risk. However it is a natural result of the convex relation between fund size and managerial ability and the negative relation between fund size and idiosyncratic risk. From Equation (12) and (13) we can easily get

$$
\sigma_{i t}=\frac{a_{t}}{2 \gamma A_{t}}
$$

which shows that controlling for fund size, idiosyncratic risk is positively correlated with managerial ability while controlling for managerial ability, idiosyncratic risk is negatively correlated with fund size. ${ }^{18}$

\subsection{The dynamics of fund size and fund flows}

From Proposition 1 we can easily derive the dynamics of the fund size.

Corollary 1. The equilibrium fund growth rate is given by

$$
\frac{d A_{t}}{A_{t}}=\frac{v_{t}^{2}}{4 b \gamma A_{t}} d t+\frac{v_{t}}{\sqrt{b \gamma A_{t}}} d Z_{t}
$$

Proof. By Ito's Lemma, we know from Equation (12) that the percentage change of fund size is given by

$$
\frac{d A_{t}}{A_{t}}=\frac{1}{4 b \gamma A_{t}}\left(d a_{t}\right)^{2}+\frac{a_{t}}{2 b \gamma A_{t}} d a_{t}
$$

Equation (15) is then derived using Equation (10) and Equation (12).

\footnotetext{
${ }^{18}$ A negative relation between idiosyncratic risk and fund size has been documented by Golec (1996), Chevalier and Ellison (1999b) and Boyson (2003).
} 
Equation (15) shows that the fund has a positive expected growth rate, which is positively related to the uncertainty about the managerial ability $v_{t}$, and negatively related to the fund size $A_{t}$. The positive expected growth rate is due to the convex relation between the equilibrium fund size and the estimated managerial ability. The convexity in this relation implies that the fund size is more responsive to the upward movement of the posterior mean of the managerial ability than to the downward movement. Since the posterior mean follows a driftless Wiener process, this asymmetric response leads to a positive drift of the fund size.

Since $d Z_{t}$ is the standardized unexpected idiosyncratic return, it measures the unexpected performance of the fund manager. Therefore, the exposure of the fund growth rate to $d Z_{t}$, i.e, $\frac{v_{t}}{\sqrt{b \gamma A_{t}}}$, is the sensitivity of fund growth to fund performance. In addition, since $Z_{t}$ follows a standard Wiener process, this exposure also determines the volatility of the fund growth rate. Equation (15) shows that the sensitivity of fund growth to fund performance, as well as the volatility of the fund growth rate, is positively related to the uncertainty about managerial ability, $v_{t}$, and negatively related to the fund size, $A_{t}$.

In the empirical literature, fund flows are normally defined as the fund's asset growth rate minus its NAV return. Since the NAV return equals the sum of capital gain and dividend yield, this suggests the following definition for fund flows:

$$
F L O W:=\frac{d A_{t}}{A_{t}}-\left(\frac{d N A V_{t}}{N A V_{t}}+\delta_{t} d t\right)
$$

This definition represents the percentage asset growth rate in excess of the growth that would have occurred if no new funds had flowed in and if all dividend had been reinvested in the fund.

Corollary 2. The rate of net fund inflows is characterized by

$$
F L O W=\left(\frac{v_{t}^{2}}{4 b \gamma A_{t}}-r-\lambda \sigma_{m}\right) d t-\sigma_{m} d W_{m t}+\frac{v_{t}-b}{\sqrt{b \gamma A_{t}}} d Z_{t}
$$

Proof. Substituting Equation (11) into (9), we get

$$
\frac{d N A V_{t}}{N A V_{t}}=\left(r+\lambda \sigma_{m}-\delta_{t}\right) d t+\sigma_{m} d W_{m t}+\sigma_{i t} d Z_{t}
$$


Substituting (15) and (18) into (16), and noting that $\sigma_{i t}=\frac{b}{\sqrt{b \gamma A_{t}}}$ due to Proposition 1, we immediately obtain Equation (17).

Corollary 2 implies a rich set of predictions on fund flow dynamics which are consistent with the stylized facts discussed in the introduction. Equation (17) shows that the net fund flows can be decomposed into three parts: the expected inflows, the response to unexpected market returns, and the response to unexpected idiosyncratic return. Both the expected inflows, $\frac{v_{t}^{2}}{4 b \gamma A_{t}}-r-\lambda \sigma_{m}$, and the sensitivity of fund flows to the unexpected idiosyncratic returns, $\frac{v_{t}-b}{\sqrt{b \gamma A_{t}}}$, are positively related to the uncertainty about managerial ability $v_{t}$ and negatively related to the fund size $A_{t}$. As we will discuss later, for reasonable parameterizations, both terms will be positive, implying a positive expected fund inflow rate and a positive response of fund flows to fund performance (see panel B of Table 1). ${ }^{19}$ However, the sensitivity of fund inflows to unexpected market returns, $-\sigma_{m}$, is always negative. Equation (17) also implies that the volatility of fund flows is positively related to the fund's exposure to the systematic risk and the uncertainty about the managerial ability, and negatively related to the fund size.

The different responses of fund flows to market returns and the fund's idiosyncratic returns can be understood in the following way: A fund will attract net inflows if and only if its internal growth rate, namely its $N A V$ return, is less than its equilibrium growth rate described by Equation (15). While the positive unexpected market return $d W_{m t}$ has a positive impact on a fund's internal growth rate, it has no influence on its equilibrium growth rate, because it does not affect the belief about managerial ability. Therefore, its influence on fund size must be offset by corresponding fund outflows. Things are different when the unexpected idiosyncratic return $d Z_{t}$ is high. Higher idiosyncratic returns not only increase the asset value but also result in a higher evaluation of managerial ability, with the latter effect generally dominating the former.

Since fund size $A_{t}$ tends to increase due to the positive expected growth rate, Equations (15) and (17) imply that the fund growth and fund inflows tend to slow down, and become less volatile and less responsive to past performance as the manager tenure increases. If the $a$ priori variance $v_{0}$ exceeds the instantaneous volatility of true ability $\omega$, then these tendencies

\footnotetext{
${ }^{19}$ Note that the positive drift and sensitivity implies a positive and convex flow-performance relation.
} 
will show up even after controlling for fund size, since the posterior variance $v_{t}$ decreases over time. These implications of our model have not yet been tested rigorously. However, some indirect support exists in the literature. For example, both Chevalier and Ellison (1997) and Boudoukh, Richardson, Stanton, and Whitelaw (2003) find that fund flows are more sensitive to past performance for young funds than for old funds. Boudoukh, Richardson, Stanton, and Whitelaw (2003) also find that young funds have higher expected percentage inflows than old funds. If we interpret young funds as funds whose managers have shorter tenure, then these findings are consistent with our model predictions as well.

\section{The optimal manager replacement rule: The case of con- stant uncertainty}

\subsection{The optimal replacement threshold}

We now examine the optimal manager replacement rule of the management company, given the relation between the fund size and the belief about managerial ability derived in the last section. Since an analytical solution is not available for the case in which the posterior variance of managerial ability, $v_{t}$, is changing over time, we first consider the case in which $v_{t}$ is constant. According to our discussion in Section 1, this corresponds to the case $\omega=v_{0}>0$. We will consider the case of time-varying posterior variance in Section 3.

To eliminate the horizon effect, we assume that manager tenure can in principle be infinitely long. However, a manager can be fired by the management company or quit at his own will. Whenever the incumbent manager departs, either because he is fired or he leaves voluntarily, the management company incurs a cost when hiring a new manager. This cost can either be interpreted as a search cost or a cost for training the new manager. The ability of the new manager is again normally distributed with mean $a_{0}$ and variance $v_{0}$. The cost is assumed to be a fixed proportion $k$ of the initial value of the management company.

Since the focus of this paper is the optimal firing decision of the management company, we do not endogenize the job quitting decision of the manager. Instead we assume that the manager's job quitting can be described by a Poisson process $q_{t}$ with a constant mean arrival 
rate $\mu$ :

$$
d q_{t}= \begin{cases}0 & \text { with probability } 1-\mu d t \\ 1 & \text { with probability } \mu d t\end{cases}
$$

The $q_{t}$ process is assumed to be uncorrelated with either the $W_{m t}$ or the $Z_{t}$ process.

The management company's problem is to determine an optimal threshold for manager replacement. This is similar to optimizing the exercise decision for the owner of an American option and can be analyzed using dynamic programming techniques. In the special case we consider now, there is only one state variable in our system, i.e., the posterior mean of the managerial ability, $a_{t}$, since the posterior variance is constant and since there is no horizon effect. Therefore the Bellman equation can be written as follows:

$$
F\left(a_{t}\right)=\max \left\{(1-k) F\left(a_{0}\right), b_{t}(1-s) A_{t} d t+e^{-r d t} E\left[F\left(a_{t}\right)+d F\left(a_{t}\right)\right]\right\} .
$$

where the value function $F\left(a_{t}\right)$ is the market value of the management company, which is the present value of all future net profits under the optimal replacement rule. On the right-hand side, the first term is the value of the management company when the manager is replaced. We call it the replacement value. The second term is the continuation value, which consists of the immediate net profit in the period from $t$ to $t+d t$ and the expected company value at $t+d t$, discounted back at the risk free rate. The risk free rate is used because the change in the market value of the management company is driven by $d Z$ and $d q$, both of which are idiosyncratic. Since the owners of the management company bear no systematic risk, the fair expected return is the risk free rate.

Since for $a_{t} \in(0,+\infty)$, which is the relevant range for our model, $b_{t}(1-s) A_{t}-r[(1-$ k)F $\left(a_{0}\right)$ ] is monotonically increasing with $a_{t}$ (note that $A_{t}$ is a quadratic function of $a_{t}$ and $(1-k) F\left(a_{0}\right)$ is a constant), there will be a single cutoff $\underline{a}$, with continuation optimal if $a_{t}$ is above $\underline{a}$ and replacement optimal otherwise. ${ }^{20}$ This is the optimal threshold that we wish to identify.

\footnotetext{
${ }^{20}$ See Dixit and Pindyck (1994), pp. 128-130.
} 
In the continuation region, the Bellman equation is

$$
r F\left(a_{t}\right) d t=b_{t}(1-s) A_{t} d t+E\left[d F\left(a_{t}\right)\right]
$$

which is a no-arbitrage condition.

Suppose that the function $F(a)$ is continuous and twice-differentiable. Using Ito's Lemma and taking into account the possibility of job quitting, we have

$$
d F\left(a_{t}\right)= \begin{cases}\frac{1}{2} F_{a a}\left(a_{t}\right) v_{0}^{2} d t+F_{a}\left(a_{t}\right) v_{0} d Z & \text { if } d q=0 \\ (1-k) F\left(a_{0}\right)-F\left(a_{t}\right) & \text { if } d q=1\end{cases}
$$

where $F_{a}\left(a_{t}\right)$ and $F_{a a}\left(a_{t}\right)$ denote the first and second order derivative of $F\left(a_{t}\right)$ with respect to $a_{t}$.

From Equation (22) and (19), we can see that the expected change of $F\left(a_{t}\right)$ is

$$
E\left[d F\left(a_{t}\right)\right]=\frac{1}{2} F_{a a}\left(a_{t}\right) v_{0}^{2} d t+\mu\left[(1-k) F\left(a_{0}\right)-F\left(a_{t}\right)\right] d t
$$

Substituting Equation (12) and (23) into (21), we get the following ordinary differential equation for $F\left(a_{t}\right)$ :

$$
(r+\mu) F\left(a_{t}\right)=\frac{1}{2} F_{a a}\left(a_{t}\right) v_{0}^{2}+\mu(1-k) F\left(a_{0}\right)+\frac{(1-s) a^{2}}{4 \gamma} .
$$

The general solution of this ordinary differential equation is

$$
F\left(a_{t}\right)=F_{0}+C(1) e^{-\sqrt{2(r+\mu)} a_{t} / v_{0}}+C(2) e^{\sqrt{2(r+\mu)} a_{t} / v_{0}},
$$

where

$$
F_{0}=\frac{\mu(1-k) F\left(a_{0}\right)}{r+\mu}+\frac{(1-s)\left[v_{0}^{2}+a_{t}^{2}(r+\mu)\right]}{4 \gamma(r+\mu)^{2}}
$$

and $C(1)$ and $C(2)$ are two constants that need to be determined by boundary conditions.

Note that $F_{0}$ is the value of the management company with managerial ability $a$ if it had 
no option to fire the manager. The rest of the company value, i.e., $C(1) e^{-\sqrt{2(r+\mu)} a_{t} / v_{0}}+$ $C(2) e^{\sqrt{2(r+\mu)} a_{t} / v_{0}}$, arises from the option to fire managers with low ability. When $a$ goes to plus infinity, the manager will never be replaced so the option becomes worthless. This asymptotic consideration implies that the undetermined constant associated with the positive square root, namely, $C(2)$, must be zero.

Furthermore, the function $F\left(a_{t}\right)$ has to satisfy the following boundary conditions:

(i). Value matching condition. At the replacement threshold $\underline{a}$, we must have

$$
F(\underline{a})=(1-k) F\left(a_{0}\right)
$$

(ii). Optimality condition. As a first order condition of optimality, we require ${ }^{21}$

$$
F_{a}(\underline{a}) \geq 0, F_{a}(\underline{a}) \underline{a}=0 .
$$

These conditions allow us to prove the following proposition:

Proposition 2. The optimal manager replacement threshold $\underline{a}$ and the initial value of the

\footnotetext{
${ }^{21}$ This is a generalized version of the smooth-pasting condition frequently used in option pricing literature, i.e.,

$$
F_{a}(\underline{a})=0
$$

We use the Kuhn-Tucker optimality condition instead of the standard smooth-pasting condition because $\underline{a}$ cannot be negative. When both the replacement cost and the uncertainty about the managerial ability are very high, it might be optimal for the management company not to replace the manager even if the posterior mean $a_{t}$ is zero, because there is still some chance that he will turn out to be or become a good manager later. However, the manager has to be replaced when $a_{t}=0$, even if it is not optimal, since otherwise the fund size will be zero and the fund will be "shut down" by fund investors.

In practice, funds may face some additional constraints, for example, the minimum size or maximum risk constraint, which may potentially result in non-optimal manager replacement. However, these types of constraints will never be binding in our model, since funds can always satisfy such constraints by lowering their fee ratio. Note, however, that although fee adjustment can help to get round those constraints, it cannot be a substitute for the manager replacement in our model, since it has no influence on the net profit of the management company.
} 
management company $F\left(a_{0}\right)$, are the solution to the following system of equations ${ }^{22}$ :

$$
\begin{aligned}
& \underline{a}= \operatorname{Max}\left[0,-\frac{v_{0}}{\sqrt{2(r+\mu)}}+\sqrt{\left.\frac{4 r \gamma(1-k) F\left(a_{0}\right)}{1-s}-\frac{v_{0}^{2}}{2(r+\mu)}\right],}\right. \\
& F\left(a_{0}\right)= \begin{cases}\frac{(1-s)\left[v_{0}^{2}+a_{0}^{2}(r+\mu)+\sqrt{2(r+\mu)} v_{0} \underline{a} e^{-\sqrt{2(r+\mu)}\left(a_{0}-\underline{a}\right) / v_{0}}\right]}{4 \gamma(r+\mu)(r+\mu k)} & \text { if } \underline{a}>0, \\
\frac{(1-s)\left[v_{0}^{2}+a_{0}^{2}(r+\mu)-v_{0}^{2} e^{\left.-\sqrt{2(r+\mu)} a_{0} / v_{0}\right]}\right.}{4 \gamma(r+\mu)\left[(r+\mu k)-r(1-k) e^{\left.-\sqrt{2(r+\mu)} a_{0} / v_{0}\right]}\right.} & \text { if } \underline{a}=0 .\end{cases}
\end{aligned}
$$

Proof. See Appendix A.

\subsection{Manager tenure}

Given the optimal manager replacement threshold and the job quitting process, we can derive the following proposition.

Proposition 3. Under the optimal replacement threshold $\underline{a}$ and the constant job quitting density $\mu$, the distribution of the manager's tenure has the following properties:

(i). The expected tenure of the manager is given by

$$
T=\frac{1}{\mu}\left[1-e^{-\frac{\sqrt{2 \mu}}{v_{0}}\left(a_{0}-\underline{a}\right)}\right]
$$

(ii). The cumulative distribution function of the manager's tenure is given by

$$
P(t)=1-e^{-\mu t}\left[2 \Phi\left(\frac{a_{0}-\underline{a}}{v_{0} \sqrt{t}}\right)-1\right]
$$

where $\Phi(\cdot)$ denotes the cumulative standard normal probability.

\section{Proof. See Appendix B.}

\footnotetext{
${ }^{22}$ Generally, there are two roots for this equation system, but only one of them makes economic sense, because the larger root of $\underline{a}$ is bigger than $a_{0}$. This root can be excluded because it implies that no manager will be employed at all.
} 
We can also derive the conditional density of manager departure and the expected managerial ability given the manager's tenure. These results are summarized in Proposition 4:

Proposition 4. Under the optimal replacement threshold $\underline{a}$ and the constant job quitting density $\mu$, we have:

(i). For a manager who has survived until $t$, the probability density of departure is given by

$$
f(t)=\mu+\frac{\left(a_{0}-\underline{a}\right) e^{-\frac{\left(a_{0}-a\right)^{2}}{2 v_{0}^{2} t}}}{\sqrt{2 \pi} v_{0} t^{\frac{3}{2}}\left[2 \Phi\left(\frac{a_{0}-\underline{a}}{v_{0} \sqrt{t}}\right)-1\right]} .
$$

(ii). For a manager who has survived until t, the expected ability is given by

$$
E\left(a_{t} \mid t\right)=\frac{a_{0}-2 \underline{a}\left[1-\Phi\left(\frac{a_{0}-\underline{a}}{v_{0} \sqrt{t}}\right)\right]}{2 \Phi\left(\frac{a_{0}-a}{v_{0} \sqrt{t}}\right)-1} .
$$

\section{Proof. See Appendix C}

One can see that while the conditional density of managerial departure is non-monotonic in tenure, the expected managerial ability is strictly increasing in tenure. Since higher managerial ability is associated with larger fund size, our model implies a positive relation between tenure and fund size.

From the probability density of managerial ability conditional on manager tenure (see Appendix C), the equilibrium relation between managerial ability and fund size (Equation (12)), and the relation between managerial ability and the value of management company (Equation (25) and Proposition 2), we can calculate the expected ratio of the management company value to the fund size as a function of manager tenure. We present this ratio numerically in the next sub-section.

\subsection{Base case results}

Panel A of Table 1 summarizes the base case parameter values. Panel B reports the fund size, idiosyncratic risk, expected rate of fund inflows and the flow-performance sensitivity of 


\section{Table 1: Base case parameter values and results}

Panel A of this table summarizes the parameter values for our base case scenario. Panel B presents results related to fund size, risk, and flows. Panel $\mathrm{C}$ reports the results related to manager replacement.

\begin{tabular}{llc}
\hline \multicolumn{3}{c}{ Panel A: Parameter values } \\
\hline$r$ & risk free rate & 0.05 \\
$b$ & management fee ratio & 0.01 \\
$s$ & variable cost as a percentage of fee income & 0.8 \\
$k$ & percentage replacement cost & 0.05 \\
$\gamma$ & measure of diseconomy of scale & $2 * 10^{-8}$ \\
$\sigma_{m}$ & exposure to systematic risk & 0.9 \\
$\lambda$ & market risk premium & 0.07 \\
$a_{0}$ & a priori mean of managerial ability & 0.2 \\
$v_{0}$ & a priori variance of managerial ability & 0.12 \\
$\mu$ & mean arrival rate of job quitting & 0.05 \\
$\omega$ & instantaneous volatility of true ability & 0.12 \\
\hline \multicolumn{4}{c}{ Panel results related to fund size, risk, and flows } \\
\hline$A_{0}$ & initial fund size \\
$\sigma_{i 0}$ & initial fund idiosyncratic risk & $5 * 10^{7}$ \\
$\frac{v_{0}}{4 b \gamma A_{0}}-r-\lambda \sigma_{m}$ & initial expected rate of fund inflows \\
$\frac{v_{0}-b}{\sqrt{b \gamma A_{0}}}$ & initial flow-performance sensitivity & 0.10 \\
\hline \multicolumn{3}{c}{ Panel C: results related to manager replacement } \\
\hline$F\left(a_{0}\right)$ & initial value of management company \\
$\frac{a}{T}$ & optimal replacement threshold & 0.202 \\
\hline \multicolumn{4}{l}{ expected manager tenure } \\
\hline
\end{tabular}

a fund with a new manager, as predicted by Proposition 1 and Corollaries 1 and 2. Panel $\mathrm{C}$ reports the initial value of the management company, the optimal threshold, and the expected tenure, as given by Proposition 2 and 3.

Under this set of parameter values, a newly hired manager will manage a fund of 50 million dollars and choose an idiosyncratic risk level of 0.10. A manager whose ability is believed to be one standard deviation above the a priori mean will manage a fund of 373 million dollars with idiosyncratic risk of 0.037. A new fund has an expected inflow rate of 0.202 and a flow-performance sensitivity of 1.1. The expected rate of fund inflows remains positive as long as the fund size is smaller than 114 million dollars. While the flowperformance sensitivity decreases with fund size, it is always positive.

The initial value of the management company is $9.93 * 10^{6}$ dollars, which is about 20 


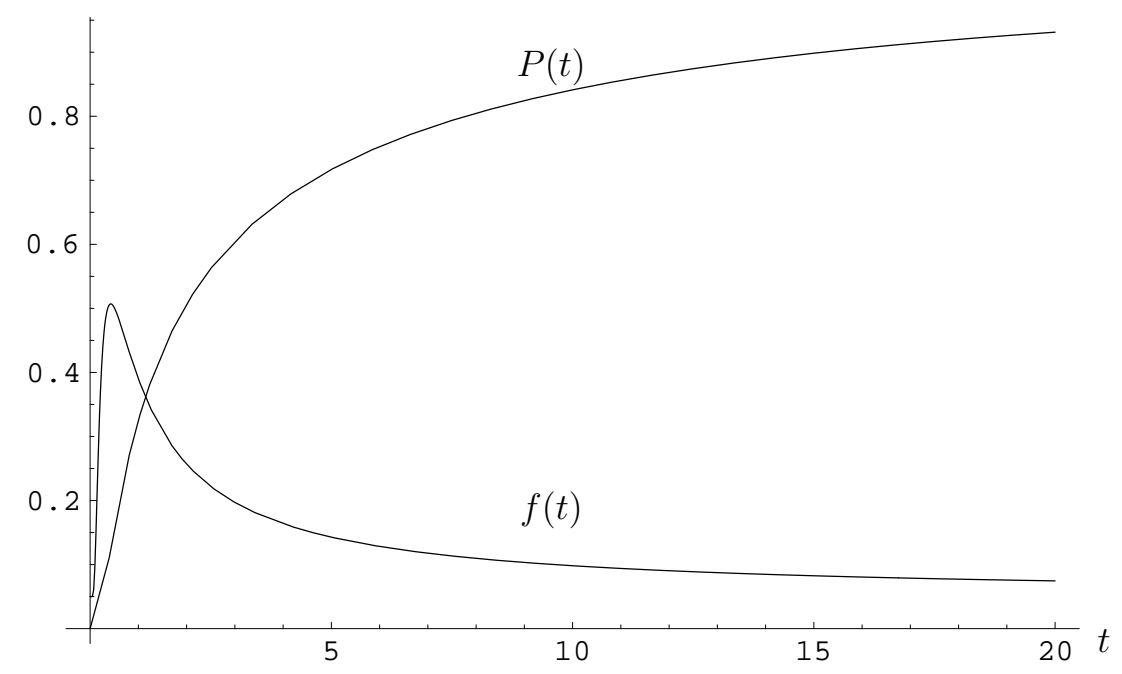

Figure 1: The base case results: manager tenure

The figure plots the cumulative distribution of manager tenure, $P(t)$, and the probability density of manager departure conditional on tenure, $f(t)$. The parameter values are given in Panel A of Table 1.

percent of the fund size. However, as we will show, the expected value of this ratio decreases very fast with manager tenure. The optimal replacement threshold is 0.0732 , which is significantly below 0.20 , the expected ability of a new manager. Since the downward movement of $a_{t}$ before it hits the replacement threshold is associated with bad performance and decreasing fund inflows, our model is consistent with the empirical findings of Khorana (1996), Khorana (2001), and Chevalier and Ellison (1999a). The expected length of of a new manager's tenure is 5.68 years under this base case parameterization.

Figure 1 plots the cumulative distribution function of manager tenure, $P(t)$, and the probability density of manager departure conditional on tenure, $f(t)$. The $P(t)$ curve shows that about $70 \%$ of the managers will have a tenure less than 5 years. The conditional density of manager departure, $f(t)$, increases rapidly when the manager starts his tenure, and then keeps going down. The non-monotonicity of the conditional departure density reflects the effect of learning and firing. Without learning and firing, the conditional departure density will always be constant due to the assumption of constant quitting density. Since it takes some time for the management company to learn about the manager's ability, the initial density of firing is low. But it goes up very quickly. As more and more incompetent managers are fired over time, managers who have survived longer will generally have a higher ability. 


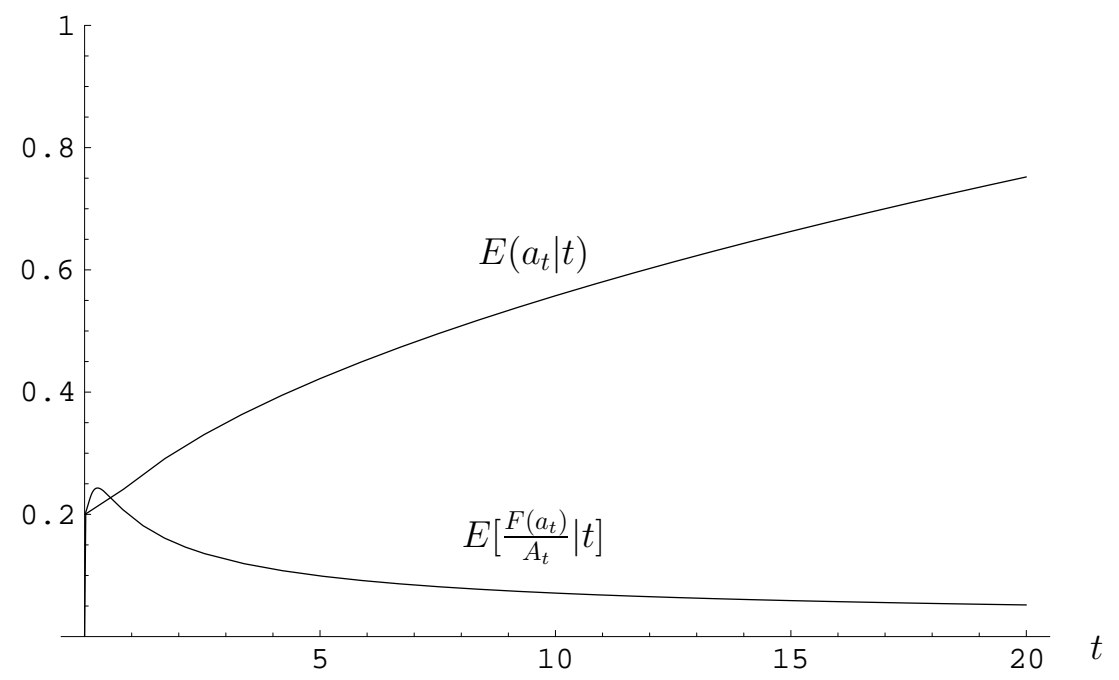

Figure 2: The base case results: managerial ability and the value-to-size ratio.

The figure plots the expected managerial ability conditional on tenure, $E\left(a_{t} \mid t\right)$, and the expected ratio of management company value to fund size conditional on tenure, $E\left[\frac{F\left(a_{t}\right)}{A_{t}} \mid t\right]$. The parameter values are given in Panel A of Table 1.

Therefore, consistent with the empirical evidence discussed in the introduction, they have a lower probability of being fired, and their departures are more likely due to non-performance reasons.

Figure 2 plots the expected managerial ability, $E\left(a_{t} \mid t\right)$, as well as the expected ratio of management company value to fund size, $E\left[\frac{F\left(a_{t}\right)}{A_{t}} \mid t\right]$, conditional on tenure. As expected, the $E\left(a_{t} \mid t\right)$ curve has an upward slope. Interestingly, the expected ratio of management company value to fund size first goes up for a short while and then keeps decreasing over tenure. After 5 years, the ratio has decreased to about 10 percent.

The decrease of the value-to-size ratio over tenure has to do with the fact that the fund's growth options decrease over time. First, since the expected managerial ability is increasing over tenure due to the firing of poor managers, the replacement option becomes less valuable over time. Note that replacing a manager is accompanied by fund inflows. Thus this source of expected fund inflows becomes less significant over the manager's tenure. Second, as we can see from Equation (15), the expected fund growth rate decreases as funds become larger even without considering manager replacement. This source of growth also depreciates over time. In the limit, when the managerial ability (and fund size) goes to infinity, both expected growth due to manager replacement and due to the convexity in the flow-performance relation 
vanish. It can be easily seen that the value-to-size ratio will converge to $\frac{(1-s) b}{r+\mu}$, which is 2 percent under our base case scenario. ${ }^{23}$

Our analysis helps to shed light on a recently documented empirical puzzle. Standard valuation methods imply that the value of management companies should be around 2030 percent of assets under management while empirical ratios are only around 2-4 percent (see Huberman (2004)). Our analysis demonstrates that extrapolating initial growth rates or assuming full dividend reinvestment is not appropriate for valuation of fund management companies, since fund size is constrained by managerial ability and real options diminish over a fund's life time. For mature funds, our model predicts ratios quite similar to the ones observed empirically. In the case where the volatility of true managerial ability is smaller than the a priori variance of managerial ability, our theoretical ratio of management company value relative to assets under management is even lower since, as we will show in Section 4, the option value of managerial replacement is less valuable.

\subsection{Comparative statics}

In this subsection we report how changes in model parameters such as the a priori mean and variance of managerial ability, replacement cost, and quitting density influence the initial value of the management company, the replacement threshold and the expected tenure. We first state some analytical results, which are derived from Proposition 2 and summarized in Proposition 5:

Proposition 5. When $\underline{a}>0,{ }^{24}$ the optimal replacement threshold $\underline{a}$, the initial value of the management company $F\left(a_{0}\right)$, and the expected manager tenure $T$, have the following prop-

\footnotetext{
${ }^{23}$ The increase of the value-to-size ratio at the beginning of tenure is due to the fact that the probability of hitting the replacement threshold is initially close to zero and that the value-to-size ratio is convex in managerial ability. When the distribution of the managerial ability is effectively not truncated, the convexity introduces a positive drift in the value-to-size ratio.

${ }^{24}$ We skip the less-realistic case where $\underline{a}=0$ for brevity, although many similar results can be derived for that case as well.
} 
erties:

$$
\begin{array}{lllll}
\frac{\partial \underline{a}}{\partial a_{0}}>0, & \frac{\partial \underline{a}}{\partial k}<0, & \frac{\partial \underline{a}}{\partial \gamma}=\frac{\partial \underline{a}}{\partial s}=0 ; & \\
\frac{\partial F\left(a_{0}\right)}{\partial a_{0}}>0, & \frac{\partial F\left(a_{0}\right)}{\partial k}<0, & \frac{\partial F\left(a_{0}\right)}{\partial \gamma}<0, & \frac{\partial F\left(a_{0}\right)}{\partial s}<0 ; \\
\frac{\partial T}{\partial k}>0, & \frac{\partial T}{\partial \gamma}=\frac{\partial T}{\partial s}=0 . &
\end{array}
$$

\section{Proof. See Appendix D.}

All the results stated in Proposition 5 are intuitive. In particular, the optimal replacement threshold $\underline{a}$ is independent of the diseconomy of scale parameter $\gamma$ and the variable cost $s$. This is because both the continuation value and the replacement value are proportional to these two parameters, so the replacement decision is not affected by them.

The effects of $v_{0}$ and $\mu$ are more difficult to sign analytically. Therefore, we resort to numerical methods. We examine the influence of one parameter at a time by fixing the values of all other parameters at the base case level. ${ }^{25}$ We then plot $F\left(a_{0}\right), \underline{a}, T$ as a function of the parameter under consideration. The parameters under consideration include $v_{0}, \mu$ as well as $a_{0}$ and $k$, although analytical results are available for the last two parameters.

Figure 3 plots the initial value of the fund management company, $F\left(a_{0}\right)$, as a function of $a_{0}, k, v_{0}$, and $\mu$ respectively. Consistent with the analytical results, $F\left(a_{0}\right)$ increases with $a_{0}$ and decreases with $k$. The figure also shows that the relation between $F\left(a_{0}\right)$ and $\mu$ is negative. This is so because a high frequency of manager quitting not only results in high replacement costs, but also implies a high probability of losing good managers. The relation between $F\left(a_{0}\right)$ and $v_{0}$ is more subtle. On the one hand, higher uncertainty about managerial ability makes the replacement decision more difficult; on the other hand, each new manager represents an option to the management company, and the value of this option increases with the heterogeneity and volatility of managerial ability. The positive relation plotted in Figure 2 shows that the latter effect is dominating.

\footnotetext{
${ }^{25}$ Note, however, that $\omega$ changes with $v_{0}$ since these two parameters must be kept the same in order to have a constant posterior variance.
} 

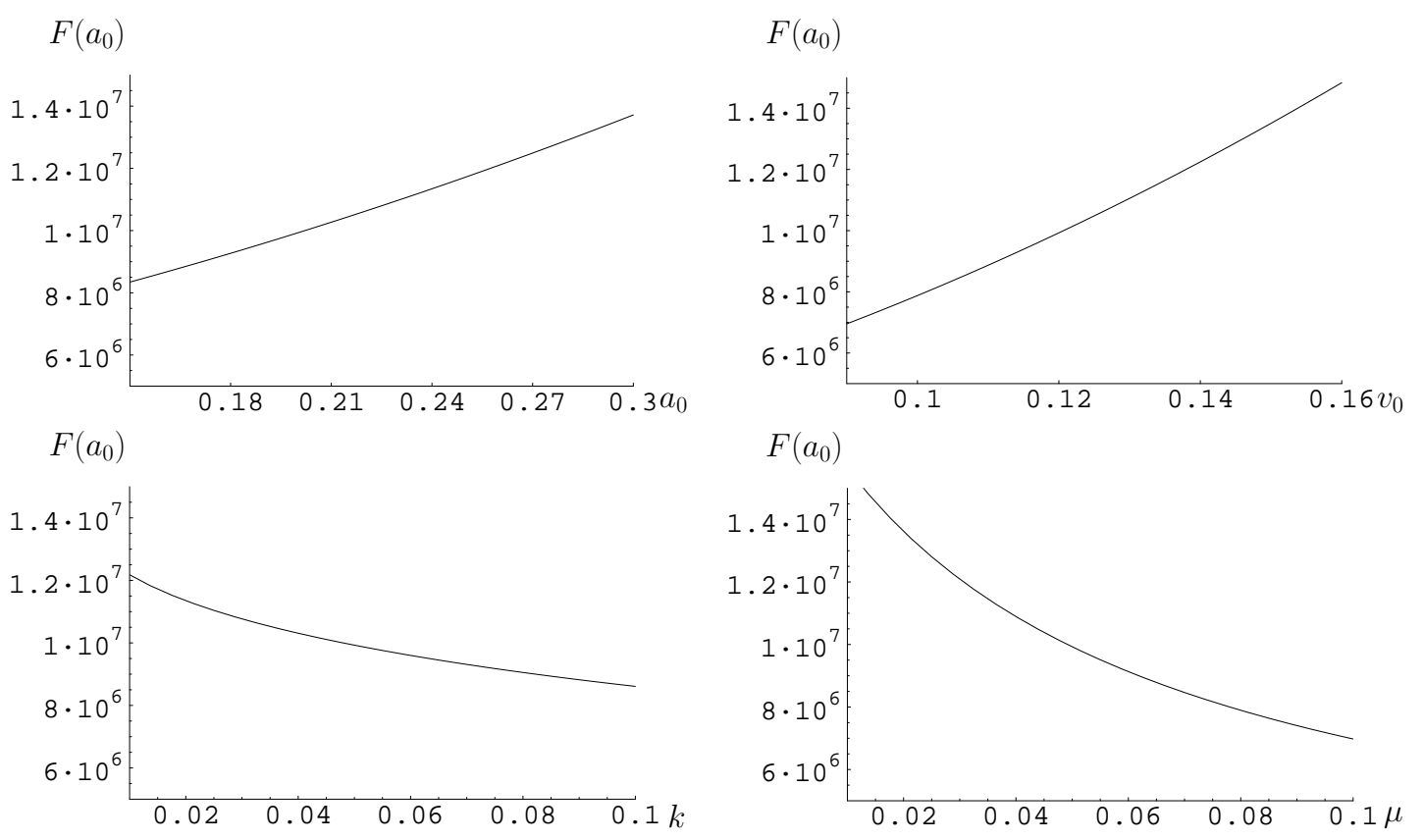

Figure 3: Comparative statics: The value of the management company

This figure plots the initial value of the fund management company, $F\left(a_{0}\right)$, as a function of $a_{0}, k, v_{0}$, and $\mu$ respectively. We examine the influence of one parameter at a time by fixing the value of all other parameters at the base case level.

Figure 4 plots the optimal replacement threshold, $\underline{a}$, as a function of $a_{0}, k, v_{0}$, and $\mu$. As expected, $\underline{a}$ increases with $a_{0}$ and decreases with $k$. As $a_{0}$ increases, $\underline{a}$ increases almost linearly, but the slope is slightly less than one. This is because higher $a_{0}$ is associated with higher value of the management company, which in turn implies higher replacement cost since the replacement cost is proportional to the company value. The figure also shows that $\underline{a}$ is negatively related to $v_{0}$. There are several reasons why this is the case: When $v_{0}$ is high, (1) the company is less sure whether a manager is good or not; (2) there is a high probability that a bad manager can become a good manager later; (3) the replacement cost is higher because the company value increases with $v_{0}$. Another message conveyed by the figure is that $\underline{a}$ is relatively insensitive to the change of the manager quitting density $\mu$. Higher frequency of manager quitting reduces the value of a management company, thus lowering the replacement cost; however, it also lowers the incentive to fire the incumbent manager, because even if the new manager is very good, his high quitting probability makes him less 

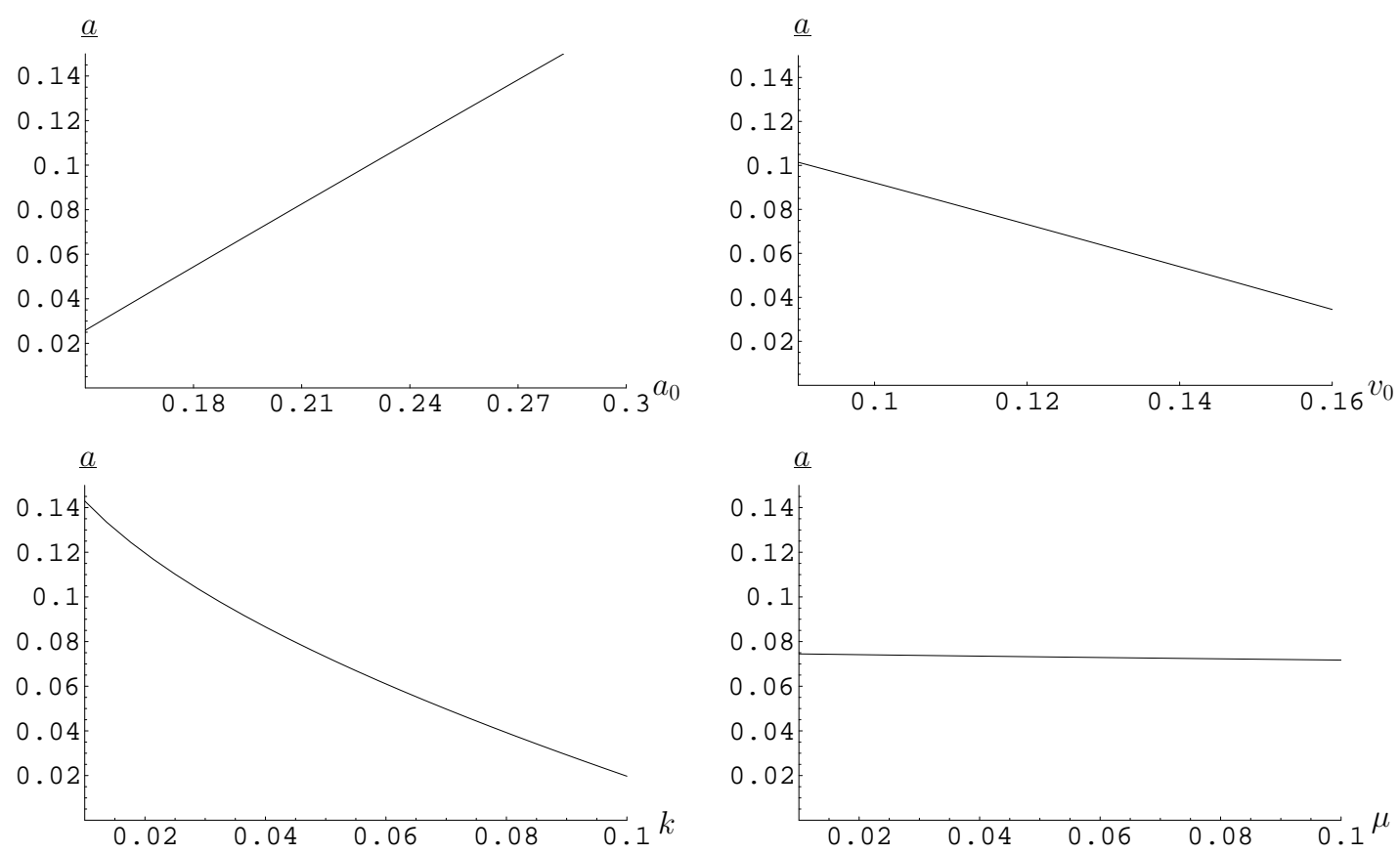

Figure 4: Comparative statics: The optimal manager replacement threshold

This figure plots the optimal manager replacement threshold, $\underline{a}$, as a function of $a_{0}, k, v_{0}$, and $\mu$ respectively. We examine the influence of one parameter at a time by fixing the value of all other parameters at the base case level.

valuable to the company. These two effects tend to offset each other, leaving the replacement threshold largely unchanged.

Figure 5 plots the expected tenure $T$ as a function of $a_{0}, v_{0}, k$, and $\mu$ respectively. It shows that $T$ increases significantly with $k$ and decreases with $\mu$. It also shows that $T$ increases slightly with $a_{0}$. This should be expected because as we have seen, the increase of $a_{0}$ does not lead to a one-to-one increase in $\underline{a}$. The slightly negative relation between $v_{0}$ and $T$ suggests that although the management company tends to adopt a less stringent threshold when the uncertainty is higher, the higher volatility of the posterior mean process still leads to a higher probability of manager firing. 

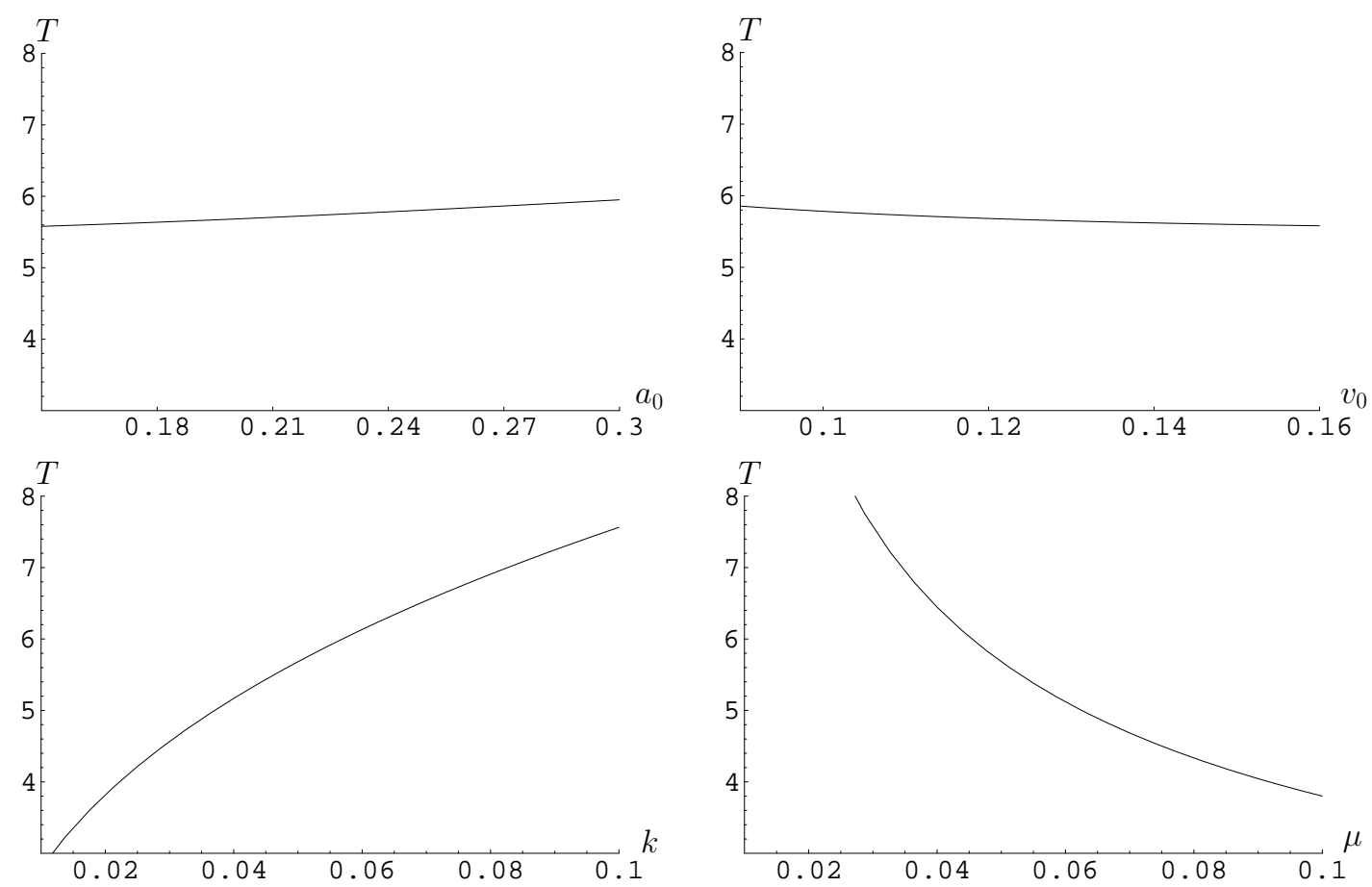

Figure 5: Comparative statics: The expected manager tenure

This figure plots the expected tenure, $T$, of a fund manager when he starts to manage an open-end fund, as a function of $a_{0}, k, v_{0}$, and $\mu$ respectively. We examine the influence of one parameter at a time by fixing the value of all other parameters at the base case level.

\section{The optimal manager replacement rule: The case of de- creasing uncertainty}

In this section we consider the case in which the volatility of the true managerial ability is lower than the a priori variance, i.e., $\omega<v_{0}$. As we have discussed in Section 1 , in this case the posterior variance $v_{t}$, which is given by Equation (8), declines over time and converges to $\omega$.

The determination of the optimal manager replacement rule is now more complicated since we have two state variables, the posterior mean $a_{t}$ and the posterior variance $v_{t}$. Since the posterior variance is a deterministic function of tenure, the Bellman equation for the value 
of the management company can be written as

$$
F\left(a_{t}, t\right)=\max \left\{(1-k) F\left(a_{0}, 0\right), b_{t}(1-s) A_{t} d t+e^{-r d t} E\left[F\left(a_{t}, t\right)+d F\left(a_{t}, t\right)\right]\right\} .
$$

Since for $a_{t} \in(0,+\infty), b(1-s) A_{t}-r(1-k) F\left(a_{0}, 0\right)$ is monotonically increasing with $a_{t}$ at any $t$, there exists a tenure-dependent threshold $\underline{a}(t)$, with continuation optimal when $a_{t}>$ $\underline{a}(t)$ and replacement optimal when $a_{t}<\underline{a}(t)$. In the continuation region, we must have

$$
r F\left(a_{t}, t\right) d t=b_{t}(1-s) A_{t} d t+E\left[d F\left(a_{t}, t\right)\right]
$$

This leads to the following partial differential equation:

$$
(r+\mu) F\left(a_{t}, t\right)=b_{t}(1-s) A_{t}+F_{t}\left(a_{t}, t\right)+\frac{1}{2} F_{a a}\left(a_{t}, t\right) v_{t}^{2}+\mu(1-k) F\left(a_{0}, 0\right),
$$

where $F_{t}$ denotes the partial derivative of $F$ with respect to $t, F_{a a}$ denotes the second order partial derivative of $F$ with respective to $a, A_{t}$ and $v_{t}$ are given by Equation (12) and (??) respectively.

The partial differential equation (39) has to satisfy the following boundary conditions:

(i). Value matching condition. At the replacement boundary, we must have

$$
F(\underline{a}(t), t)=(1-k) F\left(a_{0}, 0\right)
$$

(ii). Optimality condition. At the replacement boundary, we should also have

$$
F_{a}(\underline{a}(t), t) \geq 0, F_{a}(\underline{a}(t), t) \underline{a}(t)=0
$$

Since the partial differential equation (39) has no closed-form solution, we resort to numerical procedures using a binomial tree. The state variable $a_{t}$ has a nonconstant volatility, Therefore we use the approach developed by Nelson and Ramaswamy (1990) to construct a recombining tree. We find the value of the management company and the replacement 


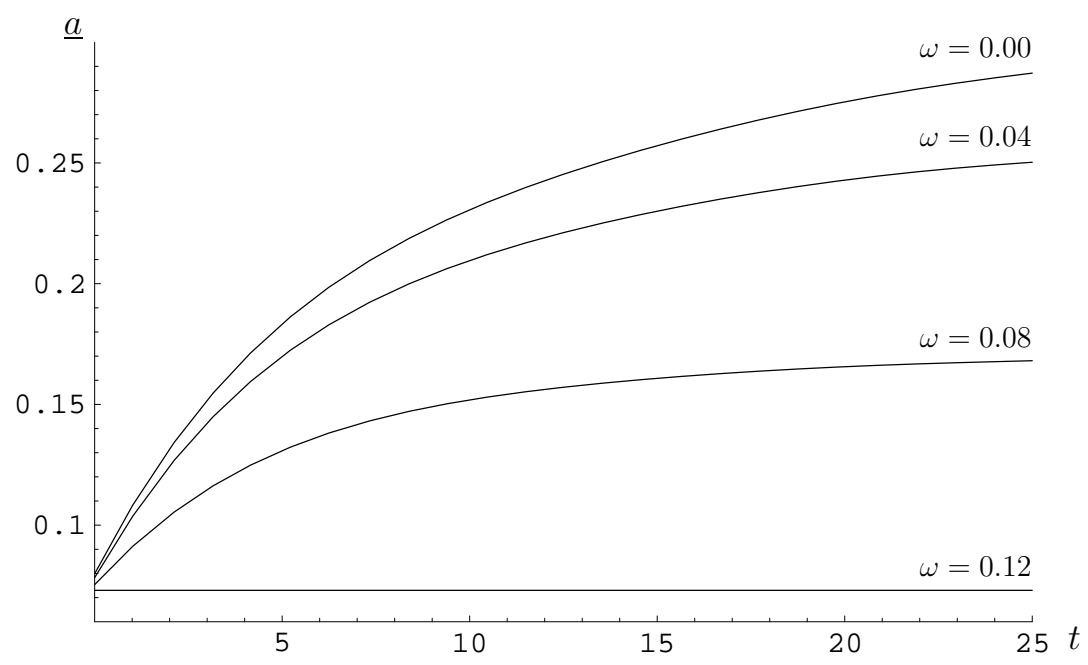

Figure 6: The optimal replacement thresholds for different values of $\omega$

This figure plots the optimal manager replacement threshold as a function of manager tenure for different values of $\omega$. The values of parameters other than $\omega$ are specified in Panel A of Table 1.

threshold recursively. ${ }^{26}$

We use the same parameter values as in Table 1 except for the volatility of true ability $\omega .^{27}$ For $\omega$, we try a series of values ranging from 0 to 0.12 . We plot the optimal replacement thresholds for $\omega=0, \omega=0.04, \omega=0.08$, and $\omega=0.12$ in Figure 6. It is striking to see that the replacement threshold increases substantially with the manager's tenure as long as the uncertainty about managerial ability decreases with tenure, i.e., as long as $\omega<v_{0}=$ 0.12. In the polar case in which the managerial ability is constant over time (i.e., $\omega=0$ ), the replacement threshold increases from approximately 0.08 for a newly hired manager, to almost 0.30 for a manager with a 25 -year's tenure! More generally, the lower the volatility of ability the higher is the threshold. Thus the management company will adopt an increasingly tougher replacement rule as the precision of the belief improves over time. This result is driven by the dynamics of the value of the real option that the portfolio manager represents. As the precision of the belief about managerial ability increases over time, the value of the manager's upside potential decreases. As a result, the management company finds it optimal to fire even a "good" manager since it becomes increasingly unlikely that this manager may

\footnotetext{
${ }^{26}$ In order to get rid of the horizon effect, we set the maximum tenure that a single manager can have to be 70 years.

${ }^{27}$ Note, however, parameters $b, \lambda$, and $\sigma_{m}$ are irrelevant for the replacement decision.
} 

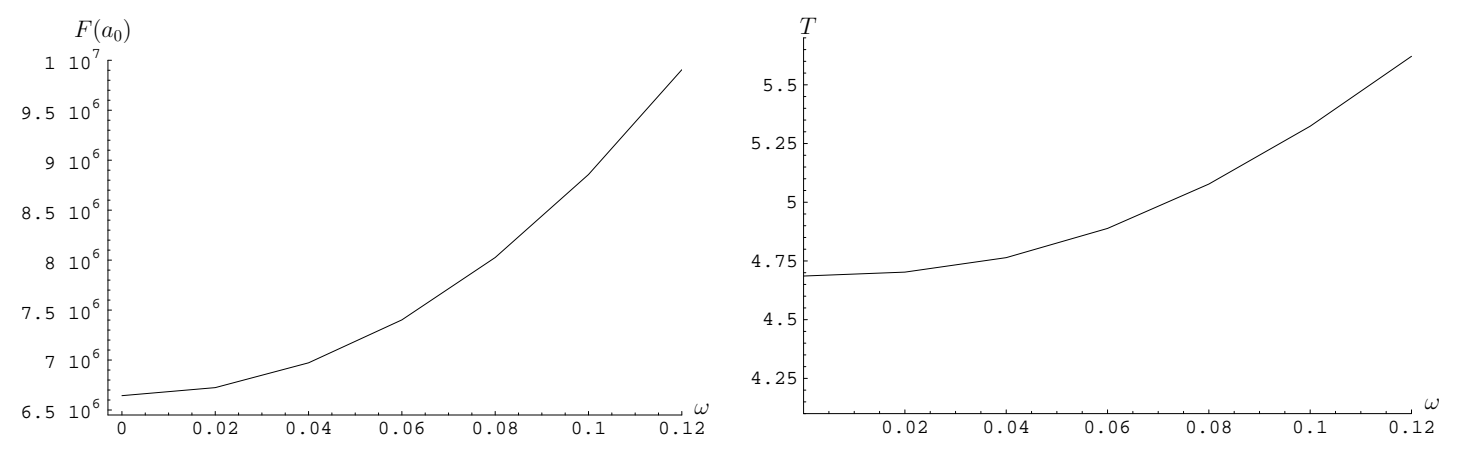

Figure 7: The value of management company and the expected tenure as a function of $\omega$

This figure plots the initial value of the management company and the expected manager tenure against the volatility of the true ability $\omega$. The values of parameters other than $\omega$ are specified in Panel A of Table 1.

become a "star". The management company is therefore willing to replace such a manager, knowing that the expected ability of the new manager is lower than the ability of the current manager. The lower expected ability of the new manager is offset by the higher real option value associated with the new manager.

By contrast, if the true ability of the manager is so volatile that the precision of the belief is constant (i.e., $\omega=v_{0}=0.12$ ), then the real option associated with a manager with long tenure is as high as the one associated with a new manager, and the replacement threshold is lower and constant over the manager's tenure, reproducing the result of the previous section.

Figure 7 plots the initial value of the management company and the expected tenure against the volatility of the true ability $\omega$. It shows that the initial value of the management company is increasing in the volatility of the true ability. Clearly this is due to the higher option value of manager replacement. Since the management company essentially owns a put option, it benefits from the variability of managerial ability. The graph also shows that the expected manager tenure is positively related to $\omega$. Although the probability of hitting a given threshold is higher when $\omega$ is higher, this effect seems to be dominated by the counter-effect of lower replacement thresholds associated with high $\omega$.

For each specific value of $\omega$, we also perform the same comparative static analysis as in Sub-section 2.4. The results are qualitatively the same. Therefore we do not report them here. 


\section{Flow responses and risk changes around manager replace-}

\section{ment}

In our model, the response of fund flows to an observed manager change can be derived from Proposition 1. Since all new managers have the same expected ability $a_{0}$, the fund size will adjust from $\frac{a_{t}^{2}}{4 b \gamma}$ to $\frac{a_{0}^{2}}{4 b \gamma}$ when a manager with ability $a_{t}$ is replaced by a new manager at time $t .^{28}$ This implies that the proportional fund inflow around a manager change is given by $\frac{a_{0}^{2}}{a_{t}^{2}}-1$. Depending on whether the posterior mean of the departing manager's ability, $a_{t}$, is higher or lower than the a priori mean $a_{0}$, the flow response to a manager change can be either negative or positive. ${ }^{29}$

From Proposition 1 we can also derive the percentage change of the fund's idiosyncratic risk surrounding a manager change, which is given by $\frac{\Delta \sigma_{i t}}{\sigma_{i t}}=\frac{a_{0}}{a_{t}}-1$. Therefore, when a manager whose ability is inferred to be higher than the a priori mean is replaced, the fund's idiosyncratic risk will go up, and vice versa.

The above results hold for manager changes due to either quitting or firing. In the following analysis, we consider only manager changes due to the firing of managers, which happen when the posterior mean of managerial ability, $a_{t}$, hits the optimal replacement threshold $\underline{a}$. Our discussion above leads to the following proposition on flow responses and risk changes around the firing of an underperforming manager.

Proposition 6. If an open-end fund manager is fired by the management company, then

(i). the fund will have a net proportional fund inflow of $\frac{a_{0}^{2}}{\underline{a}^{2}}-1$,

(ii). the fund's idiosyncratic risk will change by a percentage of $\frac{a}{a_{0}}-1$.

Our previous results show that when the uncertainty about managerial ability decreases over time, it may be the case that the optimal replacement threshold $\underline{a}$ is above the $a$ priori

\footnotetext{
${ }^{28}$ Note that investors have no incentive to respond earlier in our simplified world without transaction costs, even if the manager change is fully anticipated.

${ }^{29}$ The prediction that fund size will adjust immediately to reflect the new manager's ability is admittedly quite strong, because in reality, managerial ability is not the only determinant of fund performance. However some anecdotic evidence do show that investors are quite sensitive to fund manager changes. For example, it was reported that when William von Mueffling, a star manager running the hedge-fund business of Lazard Asset Management company, resigned in January 2003, Lazards 4 billion hedge-fund business dwindled to less than 1 billion in just a few weeks (The Economist (2003)).
} 
mean $a_{0}$. Therefore even a forced replacement might be accompanied by fund outflows and an increase of fund risk. However, even when the uncertainty about managerial ability decreases over time, most manager replacements will occur before $\underline{a}$ reaches $a_{0}$. Therefore manager replacement should in general be associated with fund inflows and a decrease of fund risk.

Using our analysis of the determinants of the optimal replacement threshold, Proposition 6 implies specific comparative static results on the flow responses and risk changes around manager firing. In particular, since the optimal replacement threshold $\underline{a}$ is negatively related to the replacement cost and the uncertainty about managerial ability, our model implies that the net fund inflows and the decrease of fund risk around manager firing are positively related to the replacement cost and the uncertainty about managerial ability. Also, since $\underline{a}$ increases with manager tenure as long as $v_{0}>\omega$, our model also implies that the flow response and the risk decrease around manager replacement should generally be negatively related to the replaced manager's tenure. The empirical test of the these comparative static results is an interesting topic for future research.

Proposition 6 also has sharp implications on the flow-performance relation. It implies that bad performance is not necessarily associated with money outflows. It can result in money inflows if a manager replacement is triggered. This introduces additional convexity in the flow-performance relation. It is in contrast with the prediction of the Berk and Green (2004) model, which does not allow for manager replacement and assumes that the fund will be shut down whenever its performance reaches a lower boundary.

Proposition 6 also provides an alternative explanation for an empirical finding documented by Khorana (2001), i.e., that the replacement of underperforming managers is preceded by an increase in the fund's idiosyncratic risk and followed by a decline in the fund's idiosyncratic risk. Although this is usually explained as evidence of gambling behavior of underperforming managers in the spirit of Chevalier and Ellison (1997) and Brown, Harlow, and Starks (1996), our result suggests that this may reflect the optimal risk-taking behavior of managers with different abilities. 


\section{Conclusion}

This paper has developed a continuous-time model in which the portfolio manager's ability is not known precisely. All parties involved, including the manager, learn about the manager's ability from past portfolio returns. In response, investors can move capital into or out of a mutual fund, portfolio managers can alter the risk of the portfolio and the management company can replace incumbent managers with new managers. Thus, the model formalizes simultaneously the external governance of the product market and the internal governance mechanism in a fully-dynamic framework, thereby generating a rich set of empirical predictions on both mutual fund flows and manager turnover.

The model shows that product market forces introduce strong incentives to monitor and replace managers of open-end funds. At the same time, this internal governance also influences how investors respond to past performance. Our analysis rationalizes many empirically documented findings, such as the decrease of proportional fund inflows and flow-performance sensitivity as funds become larger; the positive relation between manager tenure and fund size; the increase of fund risk before manager replacement followed by a subsequent decrease. At the same time, our analysis generates new empirical hypotheses which have not yet been tested. For example, our model predicts that the convexity of the flow-performance relation and the sensitivity of flows to performance decrease with manager tenure; that the probability of management replacement, as well as the ratio of the management company value to assets under management, increases at the initial stage of manager tenure and then decreases; and that the response of fund flows to an observed manager change is positively related to the manager replacement cost and to the uncertainty about managerial ability.

The framework derived in this paper can be extended in a number of ways. In particular, we have assumed that capital can be moved freely into and out of the fund. In practice this is associated with costs. In the limit, capital cannot be withdrawn or injected in a fund at all. This would be true for the case of closed-end funds. Applying this analysis to the case of closed-end funds and analyzing the resulting discounts or premia is our current subject of research. Another assumption we have made is that the departing manager leaves no "legacy" behind. As a result, a fund becomes like a new fund after the manager replacement. In prac- 
tice this may not be the case. The fund management company itself may also possess some specific expertise which does not vanish with the departing manager. Under such circumstances, the response of fund flows to manager changes will be less dramatic than the current model predicts. 


\section{Appendix}

\section{A. Proof of Proposition 2}

Proof. Since $C(2)$ must be zero by the usual asymptotic argument, from Equation (25) and the value-matching condition (26) we have

$$
\frac{\mu(1-k) F\left(a_{0}\right)}{r+\mu}+\frac{(1-s)\left[v_{0}^{2}+\underline{a}^{2}(r+\mu)\right]}{4 \gamma(r+\mu)^{2}}+C(1) e^{-\sqrt{2(r+\mu)} \underline{a} / v_{0}}=(1-k) F\left(a_{0}\right) .
$$

Furthermore, the initial value of the management company, i.e., $F\left(a_{0}\right)$, should also satisfy the general solution (25). Therefore we have

$$
F\left(a_{0}\right)=\frac{\mu(1-k) F\left(a_{0}\right)}{r+\mu}+\frac{(1-s)\left[v_{0}^{2}+a_{0}^{2}(r+\mu)\right]}{4 \gamma(r+\mu)^{2}}+C(1) e^{-\sqrt{2(r+\mu)} a_{0} / v_{0}} .
$$

Now we consider two alternative cases:

(i). $\underline{a}>0$.

If $\underline{a}>0$, then by the optimality condition (27) we will have $F_{a}(\underline{a})=0$, which implies

$$
\frac{(1-s) \underline{a}}{2 \gamma(r+\mu)}+C(1) \frac{-\sqrt{2(r+\mu)}}{v_{0}} e^{-\sqrt{2(r+\mu)} \underline{a} / v_{0}}=0 .
$$

Therefore we have

$$
C(1)=\frac{(1-s) v_{0} \underline{a}}{(2(r+\mu))^{\frac{3}{2}} \gamma} e^{\sqrt{2(r+\mu)} \underline{a} / v_{0}} .
$$

Substituting Equation (45) into (42) and collecting terms, we get

$$
\underline{a}=-\frac{v_{0}}{\sqrt{2(r+\mu)}}+\sqrt{\frac{4 r \gamma(1-k) F\left(a_{0}\right)}{1-s}-\frac{v_{0}^{2}}{2(r+\mu)}} .
$$

Substituting Equation (45) into (43), we get

$$
F\left(a_{0}\right)=\frac{(1-s)\left[v_{0}^{2}+a_{0}^{2}(r+\mu)+\sqrt{2(r+\mu)} v_{0} \underline{a} e^{-\sqrt{2(r+\mu)}\left(a_{0}-\underline{a}\right) / v_{0}}\right]}{4 \gamma(r+\mu)(r+\mu k)} .
$$


(ii). $\underline{a}=0$.

If $\underline{a}=0$, then by Equation (42) we have

$$
C(1)=\frac{r(1-k) F\left(a_{0}\right)}{r+\mu}-\frac{(1-s) v_{0}^{2}}{4 \gamma(r+\mu)^{2}}
$$

Substituting this equation into (43) and noting that $\underline{a}=0$, we have

$$
F\left(a_{0}\right)=\frac{(1-s)\left[v_{0}^{2}+a_{0}^{2}(r+\mu)-v_{0}^{2} e^{-\sqrt{2(r+\mu)} a_{0} / v_{0}}\right]}{4 \gamma(r+\mu)\left[(r+\mu k)-r(1-k) e^{-\sqrt{2(r+\mu)} a_{0} / v_{0}}\right]} .
$$

This completes our proof of Proposition 2.

\section{B. Proof of Proposition 3}

Proof. We first derive the cumulative distribution function of the manager's tenure, and then calculate the expected manager tenure.

Note that for the manager's tenure to be longer than $t$, it must be true that: (1) he has not quit before time $t$; (2) he has not been fired, i.e., the posterior mean of his ability has not hit the replacement threshold $\underline{a}$ before time $t$.

Since the job quitting follows a Poisson process, the probability that the manager did not quit before time $t$ is simply $e^{-\mu t}$. And since the posterior mean $a_{t}$ follows a Wiener Process with volatility $v_{0}$, the probability that $a_{t}$ stays above $\underline{a}$ until $t$ is given by

$$
P_{a_{0}}\left(\inf _{0<s<t} a_{s} \geq \underline{a}\right)=2 \Phi\left(\frac{a_{0}-\underline{a}}{v_{0} \sqrt{t}}\right)-1
$$

where $\Phi(\cdot)$ denotes the cumulative standard normal probability.

Due to the assumption that the quitting process $q_{t}$ is uncorrelated with the posterior mean process $a_{t}$, the joint probability that neither quitting nor firing happens before $t$ is simply the product of two marginal probabilities. Therefore, the probability that the manager survives until $t$ is

$$
P_{\text {survive }}(t)=e^{-\mu t}\left[2 \Phi\left(\frac{a_{0}-\underline{a}}{v_{0} \sqrt{t}}\right)-1\right],
$$


and the cumulative distribution function of the manager's tenure is

$$
P(t)=1-P_{\text {survive }}(t)=1-e^{-\mu t}\left[2 \Phi\left(\frac{a_{0}-\underline{a}}{v_{0} \sqrt{t}}\right)-1\right],
$$

where $P(t)$ denotes the probability that the manager's tenure is shorter than $t$.

From the cumulative distribution function $P(t)$, we can calculate the expected manager tenure $T$, which is given by

$$
T=\int_{0}^{+\infty} t d P(t)=\frac{1}{\mu}\left[1-e^{-\frac{\sqrt{2 \mu}}{v_{0}}\left(a_{0}-\underline{a}\right)}\right]
$$

This completes our proof of Proposition 3.

\section{Proof of proposition 4}

Proof. From the cumulative distribution function (31) we can derive the conditional probability that the manager departs in the time interval $[t, t+d t]$, given that he has survived until $t$. This conditional probability is given by $[P(t+d t)-P(t)] /[1-P(t)]$. Dividing the conditional probability by $d t$, we get the conditional density of manager departure $f(t)$, which is given by Equation (32).

For the expected ability of a manager with tenure $t$, first note that based on the reflection principle of the Wiener process, the unconditional density of $a_{t}$ at any $t$, given the optimal replacement threshold $\underline{a}$ and the constant quitting density $\mu$, is given by

$$
g\left(a_{t}\right)= \begin{cases}\frac{e^{-\mu t}}{v_{0} \sqrt{2 \pi t}}\left[e^{-\frac{\left(a_{t}-a_{0}\right)^{2}}{2 v_{0}^{2}}}-e^{-\frac{\left(a_{t}+a_{0}-2 a\right)^{2}}{2 v_{0}^{2} t}}\right] & \text { if } a_{t}>\underline{a}, \\ 0 & \text { if } a_{t} \leq \underline{a} .\end{cases}
$$

From the unconditional density, we can calculate the unconditional mean of $a_{t}$, which equals

$$
e^{-\mu t}\left[a_{0}-2 \underline{a}\left(1-\Phi\left(\frac{a_{0}-\underline{a}}{v_{0} \sqrt{t}}\right)\right)\right]
$$

Dividing the unconditional mean obtained above by the survival probability given by Equa- 
tion (47), we get the conditional expectation of $a_{t}$ for a manager with tenure $t$, which is given by Equation (33).

This completes our proof of proposition 4.

\section{Proof of Proposition 5}

Proof. Substituting the first equality of Equation (29) into (28), we see immediately that the optimal replacement threshold $\underline{a}$ is independent of the diseconomy of scale parameter $\gamma$ and the variable cost $s$. Using the implicit function theorem, it is not difficult to prove that

$$
\frac{\partial \underline{a}}{\partial a_{0}}>0, \quad \frac{\partial \underline{a}}{\partial k}<0
$$

Since by Equation (30), the expected tenure $T$ is negatively related to $\underline{a}$, it follows from the above results that

$$
\frac{\partial T}{\partial k}>0, \quad \frac{\partial T}{\partial \gamma}=\frac{\partial T}{\partial s}=0
$$

Noting that $\underline{a}$ is independent of $\gamma$ and $s$, we can easily see from Equation (29) that

$$
\frac{\partial F\left(a_{0}\right)}{\partial \gamma}<0, \quad \frac{\partial F\left(a_{0}\right)}{\partial s}<0
$$

Substituting $\underline{a}=-\frac{v_{0}}{\sqrt{2(r+\mu)}}+\sqrt{\frac{4 r \gamma(1-k) F\left(a_{0}\right)}{1-s}-\frac{v_{0}^{2}}{2(r+\mu)}}$ into the first equality of Equation (29), and applying the implicit function theorem, it is not difficult to show that

$$
\frac{\partial F\left(a_{0}\right)}{\partial a_{0}}>0, \quad \frac{\partial F\left(a_{0}\right)}{\partial k}<0 .
$$

This completes our proof of Proposition 5. 


\section{References}

Admati, Anat R., and Paul Pfleiderer, 1997, Does it all add up? Benchmarks and the compensation of active portfolio managers, Journal of Business 70, 323-350.

Bergstresser, Daniel, and James Poterba, 2002, Do after-tax returns affect mutual fund inflows?, Journal of Financial Economics 63, 381-414.

Berk, Jonathan B., and Richard C. Green, 2004, Mutual fund flows and performance in rational markets, forthcoming, Journal of Political Economy.

Boudoukh, Jacob, Matthew Richardson, Richard Stanton, and Robert F. Whitelaw, 2003, Valuation of mutual fund contracts, working paper.

Boyson, Nicole M., 2003, Why do experienced hedge fund managers have lower returns?, working paper.

Brennan, Michael J., 1998, The role of learning in dynamic portfolio decisions, European Finace Review 1, 295-306.

Brown, Keith C., W. V. Harlow, and Laura T. Starks, 1996, Of tournaments and temptations: An analysiss of managerial incentives in the mutual fund industry, Journal of Finance 51, $85-110$.

Chen, Joseph, Harrison Hong, Ming Huang, and Jeffrey D. Kubik, 2004, Does fund size erode mutual fund performance? The role of liquidity and organization, forthcoming, American Economic Review.

Chevalier, Judith, and Glenn Ellison, 1997, Risk taking by mutual funds as a response to incentives, Journal of Political Economy 105, 11671200.

Chevalier, Judith, and Glenn Ellison, 1999a, Career concerns of mutual fund managers, Quarterly Journal of Economics 114, 389-432.

Chevalier, Judith, and Glenn Ellison, 1999b, Are some mutual fund managers better than others? Cross-sectional patterns in behaviour and performance, Journal of Finance 54, $875-899$.

Daniel, Kent, Mark Grinblatt, Sheridan Titman, and Russ Wermers, 1997, Measuring mutual fund performance with characteristic-based benchmarks, Journal of Finance 52, 10351058 .

Das, Sanjiv Ranjan, and Rangarajan K. Sundaram, 2002, Fee speech: signaling, risk-sharing, and the impact of fee structures on investor welfare, Review of Financial Studies 15, 14651497.

Ding, Bill, and Russ Wermers, 2004, Mutual fund "stars": the performance and behavior of U.S. fund managers, working paper.

Dixit, Avinash K., and Robert S. Pindyck, 1994, Investment under uncertainty, Princeton University Press.

Edelen, Roger M., 1999, Investor flows and the assessed performance of open-end mutual funds, JOurnal of Financial Economis 53, 439-466. 
Elton, Edwin J., Martin J. Gruber, and Christopher R. Blake, 2003, Incentive fees and mutual funds, Journal of Finance 58, 779-804.

Fama, Eugene F., and Michael C. Jensen, 1983, Agency problems and residual claims, Journal of Law and Economics 26, 275-302.

Fortin, Rich, Stuart Michelson, and James Jordan-Wagner, 1999, Does mutual fund manager tenure matter?, Journal of Financial Planning August Issue, 72-79.

Gennotte, G., 1986, Asset pricing in an economy with incomplete information, Journal of Finance 61, 383-392.

Golec, Joseph H., 1996, The effects of mutual fund managers characteristics on their portolio performance, risk and fees, Financial Service Review 5, 133-148.

Grinblatt, Mark, and Sheridan Titman, 1993, Performance measurement without benchmarks: An examination of mutual fund returns, Journal of Business 66, 47-68.

Gruber, Martin, 1996, Another puzzle: The growth in actively managed mutual funds, Journal of Finance 51, 783-810.

Guercio, Diane Del, Larry Y. Dann, and M. Megan Partch, 2003, Governance and boards of directors in closed-end investment companies, Journal of Financial Economics 69, 111152.

Heinkel, Robert, and Neal Stoughton, 1994, The dynamics of portfolio management contracts, Review of Financial Studies 7, 351-387.

Hu, Fan, Alastair R. Hall, and Campbell R. Harvey, 2000, Promotion or demotion? An empirical investigation of the determinants of top mutual fund manager change, working paper.

Huberman, Gur, 2004, What is the NPV of expected future profits of money managers?, Working paper.

Indro, Daniel C., Christine X. Jiang, Michael Y. Hu, and Wayne Y. Lee, 1999, Mutual fund performance: does fund size matter?, Financial Analysts Journal 55, 74-87.

Ippolito, Richard A., 1992, Consumer reaction to measures of poor quality, Journal of Law and Economics 35, 4570.

Jegadeesh, Narasimhan, and Sheridan Titman, 1993, Return to buying winners and selling losers: implications for stock market efficiency, Journal of Finance 48, 65-91.

Jovanovic, Boyan, 1979, Job matching and the theory of turnover, Journal of Political Economy 87, 973-990.

Khorana, Ajay, 1996, Top management turnover: an empirical investigation of mutual fund managers, Journal of Financial Economics 40, 403-427.

Khorana, Ajay, 2001, Performance changes following top management turnover: evidence from open-end mutual funds, Journal of Financial and Quantitative Analysis 36, 371-393.

Lipster, R. S., and A. N. Shiryayev, 1978, Statistics of random process, Springer-Verlag. 
Lynch, Anthony W., and David K. Musto, 2003, How investors interpret past fund returns, Journal of Finance 58, 2033-2058.

Nelson, Daniel B., and Krishna Ramaswamy, 1990, Simple binomial processes as diffusion approximations in financial models, Review of Financial Studies 3, 393-430.

Ou-Yang, Hui, 2003, Optimal contracts in a continuous-time delegated portfolio management problem, Review of Financial Studies 16, 173-208.

Perold, Andre, and Robert S. Salomon, 1991, The right amount of assets under management, Financial Analysts Journal 47, 31-39.

Sapp, Travis, and Ashish Tiwari, 2004, Does the stock return momentum explain the "smart money" effect?, forthcoming, Journal of Finance.

Sirri, Erik R., and Peter Tufano, 1998, Costly search and mutual fund flows, Journal of Finance 53, 1589-1622.

Stoughton, Neal, 1993, Moral hazard and portfolio management problem, Journal of Finance 48, 2009-2028.

The Economist, 2003, Alpha males; Star fund managers, ,volume 367, no. 8318, 84-85 April $5,2003$.

Tufano, Peter, and Matthew Sevick, 1997, Board structure and fee-setting in the U.S. mutual fund industry, Journal of Financial Economics 46, 321-355.

Warther, Vincent A., 1995, Aggregate mutual fund flows and security returns, Journal of Financial Economics 39, 209-235.

Wermers, Russ, 2000, An empirical decomposition into stock-picking talent, style, transaction costs and expenses, Journal of Finance 55, 1655-1694.

Xia, Yihong, 2001, Learning about predictability: The effect of parameter uncertainty on dynamic asset allocation, Journal of Finance 56, 205-246.

Zheng, Lu, 1999, Is money smart? A study of mutual fund investors' fund selection ability, Journal of Finance 54, 901-933. 